\title{
Characterization of the Amaranthus palmeri physiological response to glyphosate in susceptible and resistant populations
}

\author{
Manuel Fernández-Escalada, Miriam Gil-Monreal, Ana Zabalza and \\ Mercedes Royuela*
}

Departamento Ciencias del Medio Natural, Universidad Pública de Navarra, Campus Arrosadía, E-31006 Pamplona, Spain.

* To whom correspondence should be addressed. Telephone: + 34-948169120. Fax: + 34-948168930. E-mail: royuela@unavarra.es 
1 ABSTRACT: The herbicide glyphosate inhibits the plant enzyme 5-

2 enolpyruvylshikimate3-phosphate synthase (EPSPS) in the aromatic amino acid (AAA)

3 biosynthetic pathway. The physiologies of an Amaranthus palmeri population

4 exhibiting resistance to glyphosate by EPSPS gene amplification (NC-R) and a

5 susceptible population (NC-S) were compared. The EPSPS copy number of NC-R

6 plants was 47.5-fold than the copy number of NC-S plants. Despite that the amount of

7 EPSPS protein and activity were higher in NC-R plants than in NC-S plants, the AAA

8 concentrations were similar in both concentrations. The increases in total free amino

9 acid and in AAA contents induced by glyphosate were more evident in NC-S plants. In

10 both populations, the EPSPS protein increased after glyphosate exposure, suggesting

11 transcriptional regulation. EPSPS activity seems tightly controlled in vivo by

12 coordinated transcriptional and post-transcriptional regulation. Carbohydrate

13 accumulation and a slight induction of ethanol fermentation were detected in both

14 populations.

15

16 KEYWORDS: Free amino acid accumulation, carbohydrate accumulation, ethanol

17 fermentation, herbicide resistance, physiological effects 
19 Over the past three decades, the herbicide glyphosate has revolutionized modern agriculture.

20 Glyphosate is a once-in-a-century herbicide that stands alone in many categories. ${ }^{1}$ This broad-

21 spectrum, systemic herbicide is the most widely used herbicide in the world. Glyphosate inhibits

22 the biosynthesis of the aromatic amino acids (AAAs) tryptophan (Trp), tyrosine (Tyr) and

23 phenylalanine (Phe). The primary site of action of glyphosate is the specific inhibition of a key

24 step in the shikimate pathway catalyzed by the enzyme 5-enolpyruvylshikimate-3-phosphate

25 synthase (EPSPS) (EC 2.5.1.19), which converts shikimate-3-phosphate and

26 phosphoenolpyruvate to 5 -enolpyruvylshikimate-3-phosphate in plastids. $^{2}$

27 Although chemical management has been very effective for weed control, it has also resulted in

28 the evolution of resistant weeds. Initially, glyphosate controlled most weeds, but as early as

29 1997, glyphosate-resistant weeds were reported. ${ }^{3}$ Glyphosate was widely used in non-

30 agricultural areas, but the the introduction of genetically modified crops such as corn, cotton and

31 soybean exacerbated the evolution of resistance to glyphosate. ${ }^{4}$ In this context, glyphosate is

32 used as a stand-alone weed control method on several million hectares of crop land. The

33 intensive use of glyphosate has resulted in evolution of resistance to this herbicide in several

34 problematic weeds to what had been a very effective herbicide. To date resistance to glyphosate

35 has been documented in 32 species. $^{3}$ Glyphosate-resistant weeds now pose a serious challenge

36 to modern agricultural practices and are likely to increase the cost of production. ${ }^{5}$

37 The toxic effect of glyphosate cannot be considered only in terms of its interaction at the target

38 site. The inhibition of EPSPS results in a metabolic roadblock, with physiological consequences

39 leading to plant death. Thus, even though the changes in physiological plant processes induced

40 by glyphosate have not been considered as primary effects, these changes contribute to the toxic

41 effects of glyphosate.

42 Despite its widespread use in global crop production, the precise mechanisms by which

43 glyphosate kills plants remain unclear, despite studies using new molecular methods such as 
44 transcriptional comparison, ${ }^{6,7}$ proteomic approaches ${ }^{8}$ and metabolomic profiling. ${ }^{9,10}$ In general,

45 after the target of an inhibitor has been affected, death can occur due to different causes. First,

46 plant death could result from an accumulation or increased availability of the substrates of the

47 inhibited enzymatic pathway. Second, death could be associated with the lack of end products

48 generated by the inhibited pathway (mainly AAAs). Third, lethality could be associated with

49 several side reactions triggered after the inhibition of the target because the dysregulation

50 caused by the inhibition of this pathway can lead to effects on different metabolic pathways.

51 The main metabolite that accumulates upstream of EPSPS is shikimate. Massive levels of

52 shikimate have been detected in plant tissues ${ }^{11,12}$ because inhibition at the level of EPSPS causes

53 feedback loops that drive an increased flow of carbon through the shikimate pathway, thereby

54 exacerbating the accumulation of shikimate. Moreover, toxic effects of shikimate accumulation

55 have been proposed. ${ }^{13}$

56 Some authors assume that AAA production at a level insufficient to maintain necessary protein

57 synthesis is the main effect of glyphosate exposure, and this mechanism is consistent with the

58 slow development of injury symptoms and the lack of essential plant compounds leading to

59 plant death. ${ }^{1}$ However, although a transient decrease has sometimes been reported, ${ }^{14}$ the AAA

60 content does not decrease significantly ${ }^{14}$ due to an increase in protein turnover and concomitant

61 total free amino acid accumulation ${ }^{15,16}$ and soluble protein decrease..$^{10,15}$

62 In relation to the side reactions, the blockage of the shikimate pathway by glyphosate has

63 recently been suggested to reverberate across other biochemical pathways. ${ }^{10}$ Deregulation at the

64 level of PEP that is not consumed by the inhibited EPSPS in the shikimate pathway can directly

65 affect carbon metabolism. ${ }^{13,17}$ In this sense, glyphosate can also impair carbon metabolism by

66 interfering with sugar metabolism and translocation. Carbohydrate accumulation has been

67 detected in both the leaves and roots of treated pea plants, and ethanolic fermentative

68 metabolism is enhanced by glyphosate. ${ }^{18}$ 
69 Amaranthus palmeri is among the three most troublesome weeds in the main crops in Georgia

70 (cotton, peanut, and soybean) and is among the top five most troublesome weeds in most other

71 southeastern states. This annual weed is highly problematic due to its competitiveness,

72 aggressive growth habit and prolific seed production. ${ }^{19}$ A. palmeri was initially controlled by

73 glyphosate in glyphosate-resistant crops but become a major glyphosate-resistant weed that

74 occurs in several states. Glyphosate-resistant A. palmeri was first reported in $2006,{ }^{19}$ and the

75 mechanism of resistance was gene amplification. ${ }^{20}$ This was the first reported occurrence of

76 gene amplification in a field-evolved resistance to any herbicide. ${ }^{21}$ The EPSPS gene was

77 amplified from 2 to more than 100-fold compared with sensitive populations. This mechanism

78 of resistance to glyphosate has since been reported in a number of other species, including

79 Amaranthus tuberculatus, ${ }^{22,23}$, Amaranthus spinosus, ${ }^{24}$ Kochia escoparia, ${ }^{25}$ Lolium

80 multiflorum, ${ }^{26,27}$ and Bromus diandrus. ${ }^{28}$

81 The availability of a biotype with overexpression of the EPSPS enzyme provides an opportunity

82 to analyze how overexpression of ESPS affects AAA synthesis and other physiological factors

83 by comparison with a sensitive population. In addition, comparing the different effects of

84 glyphosate on both populations will facilitate the comprehensive elucidation of the phenotypic

85 manifestations of evolved glyphosate resistance. For this purpose, biomass, shikimate

86 accumulation, EPSPS expression and activity, free amino acid profile, carbohydrate content and

87 ethanol fermentation were compared in two populations of A. palmeri (one susceptible and the

88 other glyphosate-resistant due to gene amplification). 


\section{MATERIALS AND METHODS}

90 Plant material and treatment application. The seeds of the Amaranthus palmeri biotypes

91 (NC-R and NC-S) were kindly provided by Dr. Gaines (Colorado State University, Fort Collins,

92 CO, USA) and were originally collected from North Carolina (USA). ${ }^{29}$

93 Seeds were surface sterilized prior to germination. ${ }^{30}$ For germination, seeds were incubated for 7

94 days at $4{ }^{\circ} \mathrm{C}$ in darkness and then maintained for $48 \mathrm{~h}$ in a light/darkness cycle of of $16 \mathrm{~h} / 8 \mathrm{~h}$ at

95 temperature of $30^{\circ} \mathrm{C}$ in light and $8 \mathrm{~h}$ at $18^{\circ} \mathrm{C}$ in darkness. The seeds were then transferred to

96 aerated 2.7-L hydroponic tanks in a phytotron (day/night: $16 \mathrm{~h} / 8 \mathrm{~h}$; light intensity: $500 \mu \mathrm{mol} \mathrm{s}{ }^{-1}$

$97 \mathrm{~m}^{-2} \mathrm{PAR}$; temperature: $22^{\circ} \mathrm{C} / 18^{\circ} \mathrm{C}$; relative humidity of the air: $60 / 70 \%$ ). Throughout the course

98 of the experiment, the plants remained in the vegetative phenological stage. The nutrient

99 solution $^{31}$ was supplemented with $15 \mathrm{mM} \mathrm{KNO}_{3}$.

100 In vivo shikimate assay. Shikimate accumulation following glyphosate treatment was

101 compared between NC-R and NC-S as described previously. ${ }^{32}$ Leaf discs $4 \mathrm{~mm}$ in diameter (6-

10210 discs) were excised from the youngest leaf of 3-6 plants of each biotype using a Harris Uni-

$103 \operatorname{Core}^{\mathrm{TM}}$ (Healthcore, Bucks, UK).

104 Briefly, one disc was placed in a well of a 96-well microtiter plate. Each well contained $100 \mu \mathrm{L}$

105 of a solution containing $169,84.5,42.3,21.1,10.6,5.3,2.6,1.3$ or 0 mg glyphosate $\mathrm{L}^{-1}$

106 Glyphosate was diluted from commercial formula (Glyfos, BayerGarden, Valencia, Spain).

107 Each row of the microtiter plate contained a different glyphosate concentration. The plates were

108 incubated at $22^{\circ} \mathrm{C}$ under continuous light for $16 \mathrm{~h}$. After incubation, the plants were placed in a

109 freezer $\left(-20^{\circ} \mathrm{C}\right)$.

110 The concentration of shikimate in each cell was measured according to the procedure of

111 Cromartie and Polge. ${ }^{33}$ Shikimate was extracted from the freeze-thawed leaf discs by adding 25

$112 \mu \mathrm{L}$ of $1.25 \mathrm{~N} \mathrm{HCl}$ and incubating the plates at $60{ }^{\circ} \mathrm{C}$ for $15 \mathrm{~min}$. Two $25-\mu \mathrm{L}$ aliquots from each

113 well were transferred to a new plate, and $100 \mu \mathrm{L}$ of $0.25 \%$ periodic acid $/ 0.25 \%$ metaperiodate

114 was added to each well. After the periodic acid-metaperiodate incubation (60 min in the dark), 
$11525 \mu \mathrm{L}$ of $0.6 \mathrm{M}$ sodium hydroxide with $0.22 \mathrm{M}$ sodium sulfite solution was added. The optical

116 density of the solution at $380 \mathrm{~nm}$ was determined spectrophotometrically. A shikimate standard

117 curve was developed by adding known amounts of shikimate to wells containing leaf discs not

118 exposed to glyphosate $\left(3,6,12,25,50\right.$ and $\left.100 \mu \mathrm{gLL}^{-1}\right)$. One microtiter plate was used for each

119 population. The study was repeated twice.

120 Dose-response studies. A dose-response study was performed to verify the previously reported

121 resistance. The dose-response relationship was established according to Seefeld et al. ${ }^{34}$ For each

122 population, plants of uniform size and appearance were selected, and 3 tanks with 4-5 plants

123 each were treated with each glyphosate dose. Both populations were treated when plants were

124 approximately 20 days old, after reaching the growth stage defined as $\mathrm{BBCH} 14 .{ }^{35}$ The

125 experiment was repeated twice.

126 Glyphosate is recommended at $0.84 \mathrm{~kg} \mathrm{ha}^{-1}$ for the control of Amaranthus sp. up to $46 \mathrm{~cm}$ in

127 height ${ }^{19}$. Glyphosate herbicide (commercial formula, Glyfos, BayerGarden, Valencia, Spain)

128 was applied using an aerograph (Mod. Definik; Sagola) connected to a compressor (Mod.

129 Werther one, Breverrato, $60 \mathrm{~W} ; 101 \mathrm{~m}^{-1} ; 2.5 \mathrm{bar}$ ). The herbicide was sprayed at a rate of $500 \mathrm{~L}$

$130 \mathrm{ha}^{-1}$, and thus the recommended field dose resulted in $1.6 \mathrm{~g}$ glyphosate $\mathrm{L}^{-1}$. The effect of

131 increasing doses of glyphosate up to three times the recommended dose $\left(0,0.042 \mathrm{~kg} \mathrm{ha}^{-1}\right.$ (only

132 for NC-S), $0.084 \mathrm{~kg} \mathrm{ha}^{-1}, 0.021 \mathrm{~kg} \mathrm{ha}^{-1}, 0.042 \mathrm{~kg} \mathrm{ha}^{-1}, 0.084 \mathrm{~kg} \mathrm{ha}^{-1}, 1.68 \mathrm{~kg} \mathrm{ha}^{-1}$ and $2.52 \mathrm{~kg} \mathrm{ha}{ }^{-}$

$133^{1}$ ) was evaluated in terms of biomass and shikimate content, an adequate indicator of

134 glyphosate-mediated plant injury. The control plants were treated with water because the inert

135 proprietary ingredients could not be obtained.

136 For biomass evaluation, the shoot and root fresh weights of each plant were determined 5 days

137 after treatment. The material was dried for $48 \mathrm{~h}$ at $75-80^{\circ} \mathrm{C}$ to obtain the dry weight.

138 Shikimate content was evaluated at 5 days after treatment. Three to six leaf discs (4 mm

139 diameter) were excised from the youngest leaf of each plant. Leaf discs were placed in a screw-

140 top 2-mL Eppendorf tube, frozen and stored at $-80^{\circ} \mathrm{C}$ until analysis. For shikimate 
141 determination, the vials were removed from the freezer, and shikimate was extracted as

142 described by Koger et al. ${ }^{36}$ First, $100 \mu \mathrm{L}$ of $0.25 \mathrm{~N} \mathrm{HCl}$ per disk was added to each vial. The

143 vials were incubated at $22^{\circ} \mathrm{C}$ for $1.5 \mathrm{~h}$ and mixed by vortexing several times. The shikimate

144 content was analyzed spectrophotometrically. ${ }^{33}$

145 Analytical determinations. After the dose-response study, a physiological study was

146 performed by comparing the effect of the $0.84 \mathrm{~kg} \mathrm{ha}^{-1}$ and $2.52 \mathrm{~kg} \mathrm{ha}^{-1}$ doses on each population

147 to untreated-plants. The experiment for the physiological study was repeated twice in time and

148 both populations were treated when plants were approximately 20 days old. Leaf and root

149 samples were obtained 3 days after treatment, $4 \mathrm{~h}$ after the beginning of the photoperiod, for

150 analytical determinations. Plant material was immediately frozen in liquid nitrogen and stored at

$151-80^{\circ} \mathrm{C}$. A palmeri frozen samples were ground to a fine powder under liquid $\mathrm{N}_{2}$ using a Retsch

152 mixer mill (MM200, Retsch $®$, Haan, Germany) maintaining separately individual plants as

153 biological repeats. The amount of tissue needed for each analysis was separated and stored at -

$15480^{\circ} \mathrm{C}$.

155 Relative genomic EPSPS gene copy number. Quantitative real-time PCR was performed to

156 determine the genomic copy number relative to acetolactate synthase (ALS) in untreated NC-S

157 and NC-R plants. Genomic DNA was extracted from approximately $0.1 \mathrm{~g}$ of previously ground

158 A. palmeri leaves. The plant material was homogenized in $375 \mu \mathrm{L}$ of $2 \mathrm{x}$ lysis buffer $(0.6 \mathrm{M}$

$159 \mathrm{NaCl}, 0.1 \mathrm{M}$ Tris-HCl (pH 8.0), 40 mM EDTA (pH 8.0), 4\% sarcosyl and 1\% SDS) and $375 \mu \mathrm{L}$

160 of $2 \mathrm{M}$ urea. One volume $(750 \mu \mathrm{L})$ of phenol-chloroform-isoamyl alcohol $(25: 24: 1)$ was added

161 to the mixture and mixed briefly. The homogenates were centrifuged at 20,000 $\mathrm{g}$ for $10 \mathrm{~min}$ at

162 room temperature. To precipitate the DNA, 0.7 volumes $(525 \mu \mathrm{L})$ of cold isopropanol was

163 added to the supernatants, and the tubes were centrifuged at $20,000 \mathrm{~g}$ for $15 \mathrm{~min}$ at $4^{\circ} \mathrm{C}$. The

164 DNA pellet was washed twice with $1 \mathrm{~mL}$ of $70 \%$ ethanol, air-dried and resuspended in $25 \mu \mathrm{L}$ of

165 resuspension buffer (10 mM Tris- $\mathrm{HCl}(\mathrm{pH} 8.0)$, containing $\left.30 \mu \mathrm{g} \mathrm{mL} \mathrm{m}^{-1} \mathrm{RNase} A\right)$. Samples were

166 briefly incubated at $37^{\circ} \mathrm{C}$ for 5 min to degrade contaminating RNAs. 
167 The extracted DNA was subsequently quantified and analyzed using a NanoDrop ND-1000

168 spectrophotometer (Thermo Fisher Scientific, Waltham, MA, USA). OD 260 and $280 \mathrm{~nm}$ were

169 read for every sample. The DNA quality was also checked using a 1\% agarose gel. Ten-fold

170 diluted DNA samples were loaded onto a $1 \%$ agarose gel and run at $75 \mathrm{~mA}$ for $35 \mathrm{~min}$. The gels

171 were visualized using a Gel DocTM 2000 system (Bio-Rad Laboratories Inc., Hercules, CA,

172 USA). DNA concentrations were adjusted to $5 \mathrm{ng}_{\mu \mathrm{L}^{-1}}$.

173 Quantitative real-time PCR was used to measure EPSPS genomic copy number relative to ALS

174 as described by Gaines et al. ${ }^{20}$ with some modifications. The following primer sets were used:

175 EPSPS-forward (5'-atgttggacgctctcagaactcttggt-3') and EPSPS-reverse (5'-

176 tgaatttcctccagcaacggcaa-3'); ALS-forward (5' -gctgctgaaggctacgct-3') and ALS-reverse (5'-

177 gcgggactgagtcaagaagtg- $\left.3^{\prime}\right)^{20}$. To determine the efficiency of the primers, a standard curve using

178 a $1 \times, 1 / 5 \times, 1 / 25 \times, 1 / 125 \times$, and $1 / 500 x$ dilution series of genomic DNA from NC-R was

179 conducted.

180 Real-time PCR amplifications were performed in an optical 96-well plate using an ABI PRISM

1817900 HT Sequence Detection System (Applied Biosystems, Foster City, CA, USA). Each

182 reaction was performed using $10 \mathrm{ng}$ of genomic DNA in a total volume of $20 \mu \mathrm{L}$ containing $1 \mathrm{x}$

183 SYBR Premix Ex Taq (Takara Bio Inc., Otsu, Shiga, Japan), $300 \mathrm{nM}$ specific forward primer

184 and $300 \mathrm{nM}$ specific reverse primer. The following thermal profile was used for all PCRs: $50^{\circ} \mathrm{C}$

185 for $2 \mathrm{~min}, 95^{\circ} \mathrm{C}$ for $1 \mathrm{~min}$ and 40 cycles of $\left(95^{\circ} \mathrm{C}\right.$ for $30 \mathrm{~s}$ and $60^{\circ} \mathrm{C}$ for $\left.1 \mathrm{~min}\right)$. Melt-curve

186 analysis was conducted with a final denaturation step of $95^{\circ} \mathrm{C}$ for $30 \mathrm{~s}, 60^{\circ} \mathrm{C}$ for $15 \mathrm{~s}$ and $95^{\circ} \mathrm{C}$

187 for $15 \mathrm{~s}$.

188 To calculate the final $\mathrm{Ct}$ values, ten biological replicates were performed, and each individual

189 sample was run in triplicate. The average increase in EPSPS copy number relative to ALS and

190 the standard deviation were calculated for each sample. The increase in EPSPS copy number

191 was expressed as $2 \Delta \mathrm{Ct}$, where $\Delta \mathrm{Ct}=(\mathrm{Ct}, \mathrm{ALS}-\mathrm{Ct}, \mathrm{EPSPS}){ }^{20}$ 
192 EPSPS extraction and activity assay. The EPSPS extraction and assay were conducted

193 following the procedures of Gaines et al. ${ }^{20}$ Briefly, $1 \mathrm{~g}$ of leaf tissue was ground to a fine

194 powder in a chilled mortar and mixed with $10 \mathrm{~mL}$ of cold extraction buffer. After

195 centrifugation, the supernatant was precipitated with ammonium sulfate (45-70\%) and desalted

196 (Zeba desalt spin columns, Pierce Biotechnology, Rockford, IL, USA). A phosphate detection

197 kit (Molecular Probes, Eugene, OR, USA) was used for the continuous measurement of

198 inorganic phosphate release for EPSPS activity. The total soluble protein in the reaction mixture

199 was $12.5 \mu \mathrm{g} / \mathrm{L}$ for the NC-S population and $1.25 \mu \mathrm{g} / \mathrm{mL}$ for the NC-R population. After

200 obtaining a background phosphate release level (10 $\mathrm{min})$, the final step was the addition of

201 shikimate-3-phosphate (up to $0.5 \mathrm{mM}$ ). Phosphate release was measured for an additional 10

$202 \min$.

203 Immunoblotting of EPSPS. Extraction and electrophoresis were performed as described

204 previously. ${ }^{37}$ First, $0.05 \mathrm{~g}$ of leaf tissue was ground with $0.2 \mathrm{~mL}$ of extraction buffer. Proteins

205 were separated by $12.5 \%$ SDS-PAGE. Western blots were produced according to standard

206 techniques. The EPSPS antibody was produced by a custom peptide facility (Agrisera AB,

207 Vännäs, Sweden) against a sequence of residues (numbers 193-206) of Palmer Amaranth

208 EPSPS (GenBank accession number FJ861242). The antibody was raised in rabbits using the

209 manufacturer's standard protocols. The primary antibody dilution was 1:2000. Antirabbit IgG

210 peroxidase (Agrisera AB, Vännäs, Sweden) was used as a secondary antibody at a dilution of

211 1:75.000. Bands were identified using an Advanced ECL chemiluminescence detection kit

212 (Amersham Life Science, Arlington Heights, IL, USA). Immunoblots were scanned using a GS-

213800 densitometer, and protein bands were quantified using Quantity One software (Bio-Rad

214 Laboratories, Hercules, CA, USA). Membrane signals were normalized according to total

215 soluble protein loading quantity.

216 Metabolite analysis and fermentative enzymes. Ground leaf and root samples $(0.1 \mathrm{~g})$ were

217 homogenized in $1 \mathrm{M} \mathrm{HCl}$ for amino acid extraction. After protein precipitation, the amino acid

218 concentrations in the supernatant were analyzed. After derivatization with FITC, amino acid 
219 content was measured by capillary electrophoresis and a laser-induced fluorescence detector as

220 described elsewhere. ${ }^{38}$ Cysteine content was determined from the same acid extracts derivatized

221 with 5-iodoacetamide fluorescein and reduced with tributylphosphine, as described previously.

$222 \quad 39$

223 The soluble carbohydrate (glucose, fructose and sucrose) content was determined in ethanol-

224 soluble extracts, and the ethanol-insoluble residue was extracted for starch analysis. ${ }^{39}$ The starch

225 and soluble sugar concentrations were determined by capillary electrophoresis as described by

226 Zabalza et al. ${ }^{40}$

227 Pyruvate decarboxylase (PDC) and alcohol dehydrogenase (ADH) activities were assayed in

228 desalted extracts as described previously. ${ }^{41}$

229 Statistical analysis. Dose-response curves based on fresh/dry weight were constructed using

230 the program Sigma Plot 12.0 to calculate the four-parameter sigmoidal log-logistic dose-

231 response model. The doses that resulted in a 50\% reduction of the fresh and dry weights were

232 calculated for each population.

233 In the analytical determinations, each mean value was calculated using samples from different

234 individual plants from the two performed experiments as replicates. The difference between

235 untreated plants of each population was evaluated using Student's t-test and confirmed as

236 significant when $\mathrm{p}<0.05$. The results of each population were subjected to separate one-way

237 ANOVA analysis (SPSS 18.0), and the means were separated using the least significant

238 difference method $(\mathrm{p}<0.05)$. For each population, significant differences are highlighted in the

239 figures by different letters. 


\section{RESULTS AND DISCUSSION}

241 Population dose response to glyphosate. The dose-response experiments confirmed

242 glyphosate resistance in the NC-R population. Figure 1A presents the effect of different doses of 243 glyphosate on shoot dry weigh accumulation 5 days after glyphosate application, expressed as a

244 percentage of untreated plants. Although the increase in shoot dry weight was highly variable

245 within each dose, the effect on each population was described by a significant four-parameter

246 log-logistic dose-response curve. The root dry weight of NC-S plants did not exhibit a dose-

247 dependent change over the range of concentrations of glyphosate used (data not shown), so it

248 was not possible to use this biomass parameter in the resistance characterization.

249 No difference in shoot dry weight accumulation was observed between the populations in the 250 absence of glyphosate (data not shown). The glyphosate concentration that reduced the shoot

251 dry weigth accumulation over 5 days by $50 \%\left(\mathrm{EC}_{50}\right)$ was $0.0897 \mathrm{~kg} \mathrm{ha}^{-1}$ for NC-S and $0.3310 \mathrm{~kg}$

$252 \mathrm{ha}^{-1}$ for NC-R, 3.7-fold greater. This difference in the $\mathrm{EC}_{50}$ is not really a resistance factor.

253 When percent survival or percent reduction in fresh weight after 21 days was used, the $\mathrm{EC}_{50}$

254 estimates were 20-18-fold higher for the NC-R biotype compared with the NC-S biotype. ${ }^{29,42}$

255 These differences in values reflect differences in methodology, in the parameter evaluated (i.e.,

256 percent survival versus inhibition of biomass growth) and the time point of assessment (time

257 since treatment). However, glyphosate-resistant biotypes from North Carolina have been

258 ereported to exhibit levels of resistance ranging from 3- to 22 -fold. ${ }^{43}$

259 The accumulation of shikimate in plant tissue can be used to distinguish resistant and

260 susceptible plants. Shikimate accumulation was observed in leaf disc tissue from NC-S plants

261 after 5 days of treatment with glyphosate concentrations greater than $0.21 \mathrm{~kg} \mathrm{ha}^{-1}$ (Figure 1B).

262 The shikimate accumulation was maximized when the plants were sprayed with $0.84 \mathrm{~kg} \mathrm{ha}^{-1}$

263 glyphosate, whereas accumulation was lower but still very noticeable at 1.68 and $2.52 \mathrm{~kg} \mathrm{ha}^{-1}$.

264 No significant shikimate accumulation was observed in the glyphosate-resistant biotype NC-R

265 at any of the doses tested and, on an expanded scale, there seems to be an effect, although much

266 less than with the NC-S. Previous studies of the same populations have indicated that shikimate 
267 increases in both biotypes as the glyphosate concentration increases, with a greater increase in

268 shikimate in the NC-S biotype. ${ }^{42}$ At glyphosate doses of $100 \mathrm{~g} \mathrm{ha}^{-1}$ or greater, the shikimate

269 concentration is always greater in the susceptible biotype. ${ }^{42}$ Due to the increased EPSPS copy

270 number, shikimate should not accumulate or may accumulate at lower levels compared to the

271 susceptible biotype.

272 This study established the doses employed in the physiological characterization: 0.84 and 2.52

$273 \mathrm{~kg} \mathrm{ha}^{-1}$. The $0.84 \mathrm{~kg} \mathrm{ha}^{-1}$ dose was chosen because the highest shikimate accumulation in NC-S

274 was observed at this dose, and thus the physiological status is expected to be strongly affected.

275 The $2.52 \mathrm{~kg} \mathrm{ha}^{-1}$ dose was chosen because it was the highest dose used and did not result in

276 shikimate accumulation in NC-R plants.

277 In vivo shikimate accumulation in leaf discs. In addition to shikimate quantification in

278 the leaves of plants 5 days after spraying with different glyphosate concentrations (Figure 1B),

279 plant sensitivity to glyphosate was evaluated by incubating excised leaf disc tissue for $24 \mathrm{~h}$ with

280 0.1-170 $\mathrm{mg} \mathrm{L}^{-1}$, glyphosate; shikimate accumulation in the leaf-discs submerged in different

281 glyphosate concentrations was analyzed in both populations. This second assay has been

282 reported to differentiate resistant from susceptible biotypes in different species. ${ }^{32}$

283 The leaf discs from the resistant biotype had less shikimate accumulation than the susceptible

284 biotype (Figure 2). Shikimate accumulation was similar in leaf discs of NC-S plants incubated

285 with $5 \mathrm{mg} \mathrm{L}^{-1}$ glyphosate and NC-R plants incubated with $170 \mathrm{mg} \mathrm{L}^{-1}$ glyphosate, the highest

286 dose of glyphosate. These results confirm the resistance of the NC-R population and are

287 consistent with previous research and with Figure 1.

288

289

290 Gene amplification was first reported as a glyphosate resistance mechanism in an A. palmeri

291 population from Georgia. ${ }^{20}$ A North Carolina glyphosate-resistant population of A. palmeri with

292 gene amplification of 22- to 63-fold was subsequently reported. Additional populations have 
293 since been identified in New Mexico and Mississippi. ${ }^{44,45}$ In this study, seeds from the North

294 Carolina population were used. To confirm the resistance mechanism, the EPSPS relative

295 genomic copy number was calculated by quantitative real-time PCR using ALS as an internal

296 standard. Consistent with previous studies, the genomes of the NC-R plants exhibited a mean

29747.5 -fold increase in the number of copies of the EPSPS gene compared to the genomes of NC-

298 S plants (Figure 3A).

299 An increased EPSPS copy number results in elevated EPSPS expression at RNA transcript

300 levels in A. palmeri, ${ }^{20,45,46}$ A $^{\text {tuberculatus }}{ }^{23}$ and Kochia scoparia ${ }^{25}$ but not Bromus diandrus. ${ }^{28}$

301 In addition to EPSPS expression, resistant plants with a greater EPSPS copy number have been

302 reported to have a higher quantity of the EPSPS protein ${ }^{20,25,45,46}$ and higher EPSPS enzyme

303 activity. ${ }^{20,23,26,45,46}$ In this study, the EPSPS protein was quantified. Immunoblotting with an

304 antibody for EPSPS resulted in a single reaction band at approximately $50 \mathrm{kD}$ (Figure 3B, top).

305 Greater EPSPS protein abundance was detected in NC-R plants; the normalized signal for

306 EPSPS was 25-fold higher in untreated NC-R plants than in NC-S plants (Figure 3B, bottom).

307 As expected, untreated NC-R plants exhibited higher specific EPSPS activity than NC-S plants

308 (Figure 3C) due to the increased levels of EPSPS protein in the total soluble protein.

309 Interestingly, the activity in NC-R plants was increased 26.5-fold compared to NC-S plants,

310 nearly identical to the 25 -fold change in EPSPS protein levels.

311 As widely reported, the glyphosate resistance level appears to increase with higher EPSPS

312 genomic copy number, ${ }^{20,27,45-47}$ increased EPSPS expression, ${ }^{20,26}$ protein content ${ }^{20}$ and specific

313 activity. ${ }^{20}$ Two exceptions have been reported: cloned resistant plants of A. palmeri from

314 Mississippi ${ }^{48}$ that did not exhibit a correlation between resistance and copy number and a line of

315 Echinochloa colona in which resistance could not be explained solely by higher EPSPS basal

316 activity. $^{49}$

317 In this study, the effect of glyphosate on the EPSPS protein content (Figure 3B) of NC-S and

318 NC-R plant was assessed. In both populations, plants treated with the higher dose exhibited an 319 increase in EPSPS protein levels (Figure 3B top, bottom). These results suggest transcriptional 
320 regulation triggered only by a high dose of glyphosate. This study is the first to report an

321 increase in EPSPS protein levels after glyphosate treatment. Increases in EPSPS mRNA levels

322 after glyphosate have been reported previously, suggesting transcriptional regulation, in

323 resistant and sensitive biotypes of Eleusine indica, ${ }^{50}$ Lolium rigidum ${ }^{51}$ and tobacco. ${ }^{52}$ By

324 contrast, in A. tuberculatus with multiple EPSPS copies, no increase in EPSPS expression was

325 detected after glyphosate application. ${ }^{23}$

326 The effect of glyphosate on the specific activity of EPSPS differed between the two populations

327 (Figure 3C). NC-R plants exhibited a dose-dependent increase in enzymatic activity with

328 glyphosate treatment, whereas NC-S exhibited a tendency toward decreased EPSPS activity as

329 the applied dose of glyphosate increased. The increase in the amount of protein in the NC-R

330 population at the highest dose of herbicide was sufficient for the concomitant increase in EPSPS

331 activity to alleviate the toxicity of the herbicide. Indeed, concomitant increases in EPSPS

332 mRNA and activity have been reported previously. ${ }^{50,51}$ EPSPS activity in NC-S plants decreased

333 with glyphosate treatment (Figure 3C). This response differed from that observed in NC-R

334 plants and demonstrates that although the amount of EPSPS protein was higher in the

335 susceptible population, the increase was not sufficient to counteract the amount of the enzyme

336 inhibitor (herbicide) present.

\section{Free amino acid profile in untreated susceptible and resistant plants}

338 If EPSPS is a bottleneck in the carbon flow through the shikimate pathway, NC-R

339 plants should possess higher AAAs biosynthetic capacity. To test this hypothesis, the free amino

340 acid profiles of NC-R and NC-S plants were compared before applying the herbicide. The total

341 free amino acid (Figure 4A and 4C) and AAA contents (Figure 5A and 5C) in leaves and roots

342 were compared. Moreover, the content of each individual amino acid in the leaves (Supporting

343 Information Figure 1) and roots (Supporting Information Figure 2) was determined, including

344 other groups of amino acids previously reported to be affected by glyphosate: ${ }^{14}$ branched-chain

345 (Val, Leu, Ile), acidic (Glu, Asp), and amide (Gln, Asn) amino acids. 
347 4C). Interestingly, no differences were detected in the AAA contents between untreated NC-R

348 plants and NC-S plants (nor in the leaves nor in the roots)-(Figure 5A and 5C, Supporting

349 Information Figures 1 and 2), as reported recently for two other populations of the same

350 species. ${ }^{10}$ The contents of nearly all individual amino acids in the leaves and roots (shown in

351 Supporting Information Figure 1 and 2) were similar for untreated plants of the two populations,

352 except Val, Leu, Ala and Glu in leaves and Tyr, Val and Asp in roots.

353

354

355

356

357

358

359

360

361

362

363

364

365

366

367

368

369

370

371

372

NC-R plants exhibited increases in EPSPS copy number, protein amount, and activity of 47.5-, 23.6- and 26.5-fold, respectively, compared to NC-S plants. However, the AAA content was the same in untreated plants of the two populations, indicating that the amount of AAA is independent of the expression of EPSPS and suggesting post-transcriptional regulation of EPSPS activity. Plants regulate carbon flux toward AAA biosynthesis at the transcriptional and post-transcriptional levels. ${ }^{53}$ Although all shikimate pathway genes have been characterized in model plants,${ }^{54}$ information on the effect of AAA levels on the expression of these genes in plants remains limited. ${ }^{53}$ In vitro studies of allosteric regulation have implied that the shikimate pathway in plants is mostly regulated at the gene expression level rather than the posttranslational level. ${ }^{55}$ Some evidence indicates that in plants, the expression of the shikimate pathway and the downstream pathway are coordinately regulated, often by the same transcription factor. ${ }^{53}$ The transcription factor EPF1 directly binds the EPSPS promoter and controls its spatial and developmental expression. ${ }^{56}$ Although EPSPS has been extensively studied in plants due to its association with glyphosate, the significance of EPSPS activity in the synthesis of AAA has not been sufficiently addressed. ${ }^{57}$ This study of NC-R plants provides insights into the tight control of the biosynthesis of AAAs by EPSPS activity in vivo, in which transcriptional and post-transcriptional regulation are coordinated.

\section{Free amino acid profile after glyphosate treatment}

Changes in the free amino acid profile after glyphosate treatment have been reported, ${ }^{14-}$ ${ }^{16,18}$ and thus this parameter can also be used as a physiological marker of herbicide activity. The 
373 total free amino acid content was higher in NC-S plants treated with glyphosate than in

374 untreated plants (Figure 4B and 4D). In both roots and leaves, the increases after treatment with

3750.84 or $2.52 \mathrm{~kg} \mathrm{ha}^{-1}$ glyphosate were similar. Total free amino acid accumulation after

376 glyphosate treatment has been reported previously in several species, including pea, ${ }^{14,15}$

377 Arabidopsis thaliana, ${ }^{16}$ maize ${ }^{58}$ and soybean. ${ }^{59,60}$ Glyphosate also increased the total free amino

378 acid content in the leaves and roots of NC-R plants in a dose-dependent manner (Figure 4B and

379 4D), although the detected increase in leaves was much lower than that in treated NC-S leaves.

380 Previous studies have observed small or no effects on this parameter in resistant soybean treated

381 with glyphosate. ${ }^{59,60}$ The observed accumulation of free amino acids in treated plants has been

382 attributed to increased protein turnover, ${ }^{15}$ and indeed, a decrease in the content of total soluble

383 protein was recently reported in glyphosate-treated A. palmeri populations. ${ }^{10}$ However, an

384 evaluation of the effects of glyphosate on the main proteolytic systems in pea revealed that not

385 all proteolytic systems increased. ${ }^{15}$

386 The free amino acid profile in NC-S revealed an important increase in the content of

387 each individual amino acid after 3 days of glyphosate treatment (Supporting Information Figure

3881 and Figure 2). In leaves, Val, Leu, Ile, Ala, Asn, Gln, Gly, Asp, Thr, Lys, Ser, Arg, His, Pro,

389 and Cys contents were higher after glyphosate treatment in a dose-dependent pattern

390 (Supporting Information Figure 1). In roots, Val, Leu, Ile, Ala, Gly, Glu, Thr, Lys, Ser, Arg, and

391 His contents were increased and in most cases the highest content was detected after treatment

392 with $0.84 \mathrm{~kg}$ /ha of glyphosate (Supporting Information Figure 2).. Branched-chain amino acid

393 content was greatly increased in the leaves and roots of NC-S plants after glyphosate treatment,

394 as reported recently. ${ }^{10}$ The effect of the herbicide on the amide group of amino acids (Gln, Asn)

395 in NC-S plants varied depending on the organ, increasing and decreasing in leaves and roots,

396 respectively. GABA ( $\gamma$-aminobutyric acid) is a non-protein amino acid that usually accumulates

397 under stress situations. GABA did not accumulate in glyphosate-treated NC-S plants. In NC-R

398 plants, the content of Val, Leu, Ile, Ala, Asn, Gln, Asp, Thr, Lys, Arg, His and Pro in leaves

399 and roots and the content of Gly and Cys only in leaves were increased 3 days after the 
400 application of the highest concentration of glyphosate. However, the accumulations were not as

401 striking as in the NC-S biotype (Supporting Information Figures 1 and 2).

402 The general increase in the content of each free amino acid due to protein turnover 403 could mask the specific change in each AAA. Thus, each individual AAA and their sum are

404 presented as a percentage of the total free amino acids instead of as absolute values (Figures 5B

405 and 5D). In general, in the NC-S population, the relative content of each AAA and the sum of

406 the three AAA contents were increased after glyphosate application. The detected increase was

407 more striking at the highest dose of glyphosate, following the same pattern as other free amino

408 acids. The absolute contents of Trp, Tyr and Phe were increased in the leaves and roots of the

409 susceptible plants after glyphosate application (Supporting Information Figures 1 and 2). Other

410 studies have shown no clear pattern in AAA content in response to glyphosate exposure. In

411 sensitive A. palmeri and soybean, only Trp accumulated after glyphosate treatment, ${ }^{10,59}$ whereas

412 rapeseed exhibited an increase in Phe concentration in response to low glyphosate

413 concentrations and no change in response to higher glyphosate concentrations. ${ }^{61}$ The AAA

414 content in NC-R plants was largely unaffected by glyphosate treatment: it was not affected in

415 roots and was only increased in leaves at a dose of $2.52 \mathrm{~kg} \mathrm{ha}^{-1}$. By contrast, metabolic profiling

416 of a resistant biotype of $A$. palmeri revealed perturbations in AAA levels after glyphosate

417 treatment. $^{10}$

may affect the AAA content. Transgenic Arabidopsis plants expressing a feedback-insensitive bacterial DHAPS exhibit higher Phe and Trp contents. ${ }^{62}$ Thus, the in vivo roles of two enzymes

421 of the shikimate pathway that are feedback regulated by AAA, chorismate mutase and

422 anthranilate synthase, remain unclear. ${ }^{55}$ In our study, the comparison of untreated plants of both

423 populations demonstrated that resistant plants with much higher EPSPS protein levels and

424 activity exhibited the same AAA content as susceptible plants. This result suggests a regulatory

425 mechanism after EPSPS expression that controls AAA content. The free amino acid content

426 reflects the biosynthesis, catabolism, use rate in protein synthesis and proteolysis of amino 
427 acids. AAAs are used not only in protein synthesis, but also in the biosynthesis of many

428 aromatic metabolites, such as phenylpropanoids.

429 Glyphosate treatment of the NC-R population revealed that inhibition of EPSPS activity

430 by the herbicide (even a small amount, as resistant plants possess a large amount of EPSPS

431 protein) induces an increase in EPSPS protein levels (Figure. 3B), demonstrating transcriptional

432 control of EPSPS. In these resistant glyphosate-treated plants, with higher EPSPS protein

433 amount, the AAA content was largely unaffected (Figure 5B and 5D), supporting that

434 transcriptional and post-transcriptional mechanisms interplay to control EPSPS in vivo.

435 Although the signal eliciting the increase in EPSPS protein synthesis has not been elucidated,

436 our results indicate that AAA content is not involved because AAA levels remained nearly

437 constant after glyphosate treatment. The response-triggering signal is proposed to be related to

438 minor changes in other intermediate metabolites, such as shikimate or chorismate.

439 The results obtained after glyphosate treatment of the susceptible population confirmed

440 the physiological effects described above for the resistant plants (an increase in EPSPS protein).

441 However, the increase in EPSPS protein in susceptible plants (Figure 3B) was insufficient to

442 overcome the effect of the herbicide, as free amino acid content was clearly increased (Figure

443 4). Indeed, the AAA content was also increased, most likely due to increased protein turnover,

444 thus confirming that AAA levels are not the signal triggering the increase in EPSPS synthesis.

445 Carbon allocation and ethanol fermentation after glyphosate treatment

446 Carbohydrate accumulation is induced by the application of glyphosate $\mathrm{e}^{10,16,18}$ and thus

447 can be used as a physiological marker of herbicide toxicity. Total soluble sugars (the sum of

448 glucose, fructose and sucrose) and starch contents were measured in the roots and leaves of both

449 populations of $A$. palmeri 3 days after treatment with glyphosate (Figure 6). Comparison of the

450 control plants (untreated) of the two populations revealed similar carbohydrate levels, although

451 several differences were detected: the control leaves and roots of the resistant biotype exhibited

452 significantly higher contents of starch and total soluble sugars, respectively, than the susceptible 
453 plants. In NC-S plants treated with the lowest concentration of glyphosate, accumulation of total

454 soluble sugars and starch in the leaves and of starch in roots was detected. Sugar accumulation

455 in NC-S plants exhibited a trend to decline to control values at the highest concentration, but

456 this behavior does not indicate recovery. On the contrary, the severity of the treatment of these

457 plants makes it difficult to maintain carbohydrate accumulation, corresponding to a possible

458 decline in carbon assimilation. ${ }^{14,40}$ This pattern was not detected in NC-R plants, where a

459 general increase in carbohydrate content was detected after both concentrations were applied.

460 Carbohydrate accumulation in the leaves and roots of pea and A. thaliana plants supplied with

461 glyphosate through the nutrient solution has been described. ${ }^{16,18}$ Moreover, it has been described

462 recently the same pattern when glyphosate was sprayed onto the leaves, evidencing that the

463 plant response was similar after foliar or residual applications. ${ }^{63}$ Glyphosate is a systemic

464 herbicide that is translocated through all the plant body independently of the site of application

465 and the detected physiological effects were similar. In these studies, accumulation in sinks and

466 sources was attributed to growth arrest. The accumulation of unused carbohydrates in sinks

467 suggests that sucrose is transported from the leaves to the roots at a higher rate than it is used in

468 the sinks. Under these conditions, the sugar gradient required for long-distance transport is

469 abolished, and carbohydrates accumulate in the leaves of treated plants because of a decrease in

470 sink strength. ${ }^{18}$

471 To evaluate another key parameter of carbon metabolism in the roots, ethanol

472 fermentation was assessed in both populations (Figure 7). Previous studies have reported the

473 induction of aerobic fermentation after EPSPS inhibition in pea and A. thaliana. ${ }^{16,18}$

474 The roots of untreated plants of both populations exhibited similar PDC activity,

475 whereas ADH activity was higher in NC-R roots. The roots of the NC-S plants exhibited an

476 increase in PDC and ADH activities after treatment with $0.84 \mathrm{~kg} \mathrm{ha}^{-1}$ and a trend to decline to

477 the control values when the highest dose of glyphosate was applied. Resistant plants only

478 exhibited induction of ADH activity at the highest treatment. Fermentative induction after 
479 treatment with glyphosate cannot be easily explained, and the fermentative response can likely

480 be considered a physiological effect induced under stress. ${ }^{18}$

481 Collectively, these results indicate that A. palmeri exhibits the physiological markers

482 typical of the toxic consequences of glyphosate and reported previously in other species (with

483 some deviations): total free amino acid accumulation, carbohydrate accumulation and ethanol

484 fermentation induction (only at the lowest dose applied). Although both populations exhibited

485 these symptoms, the pattern was not similar for all effects detected. Carbohydrate accumulation

486 and ethanol fermentation were detected in NC-S and NC-R plants to a similar extent, although a

487 trend to decline to control values was detected in NC-S plants treated with $2.52 \mathrm{~kg} \mathrm{ha}^{-1}$, most

488 likely due to the severity of the dose. By contrast, individual and total free amino accumulation

489 were less pronounced in NC-R plants than in NC-S plants. Free amino acid accumulation

490 induced by glyphosate was alleviated in the resistant plants due to their reduced susceptibility to

491 herbicide phytotoxicity, and thus this physiological marker was more directly related to the

492 severity of the treatment and lethality. One important exception in the free amino acid content is

493 that AAA content remained constant after glyphosate treatment, suggesting tight control of

494 EPSPS activity in vivo at the transcriptional and post-transcriptional levels. Different

495 physiological patterns of sensitive and resistant biotypes after glyphosate treatment have

496 recently been described by metabolic profiling. ${ }^{10}$ As proposed in that study, resistance to

497 glyphosate in NC-R plants, although primarily conferred by the EPSPS gene amplification, may

498 be complemented by other physiological responses, such as an anti-oxidative protective

499 mechanism (detected in ${ }^{10}$ ) or the maintenance of a constant AAA content level detected in our 500 study.

501 In conclusion, this study shows a complex regulation of EPSPS activity by

502 transcriptional and post-transcriptional mechanisms. In both populations, the herbicide induced

503 increase of the EPSPS protein, indicating a transcriptional regulation that can be useful in the

504 new weed management strategy based on RNA interference technology (branded BioDirect ${ }^{\mathrm{TM}}$ )

505 to overcome glyphosate resistance in weeds. ${ }^{64}$ No inherent differences in AAA content between 
506 the biotypes in the absence of glyphosate were found, despite the massive amount of EPSPS

507 enzyme detected in NC-R plants. Moreover, AAA content was maintained constant in resistant

508 plants, even with the glyphosate-induced increase of EPSPS enzyme. These results indicate a

509 post-transcriptional regulation at the level of EPSPS, whose signal remains unknown but can

510 not be AAA content. On the other hand, it has been possible to describe new insights of the

511 physiological manifestations of the evolved glyphosate resistance. The physiological markers

512 that have been reported before after glyphosate treatment were detected in susceptible and

513 resistant plants: Carbohydrate accumulation, induction of ethanol fermentation and free amino

514 acid accumulation. Resistant plants accumulate less amino acids than susceptible plants and the

515 effect of glyphosate on AAA content was almost abolished in resistant plants, suggesting that a

516 constant free amino acid pool and AAA content are key parameters in complementing the

517 resistance in NC-R population.

\section{Funding}

519 This work was financially supported by a grant from the Ministerio Español de Economía y

520 Competitividad (AGL-2013-40567R). M. F-E and M. G-M received funding from fellowships

521 through the Universidad Pública de Navarra.

\section{ABBREVIATIONS USED}

523 AAAs, aromatic amino acids; DHAPS, 3-deoxy-D-arabinoheptulosonate 7-phosphate synthase;

524 EPSPS, 5-enolpyruvylshikimate-3-phosphate synthase; PDC, pyruvate decarboxylase; PCR, 525 polymerase chain reaction; ADH, alcohol dehydrogenase; ALS, acetolactate synthase

\section{ACKNOWLEDGEMENTS}

527 We thank Gustavo Garijo, Oscar Armendáriz and Amaia Crespo for technical assistance. Dr.

528 Todd A. Gaines (Colorado State University, Fort Collins, CO, USA) is acknowledged for

529 providing seeds of both populations. 


\section{REFERENCES}

(1) Duke, S. O.; Powles, S. B. Glyphosate: a once-in-a-century herbicide. Pest Manag. Sci. 2008, 64 (4), 319-325.

(2) Steinrucken, H. C.; Amrhein, N. The herbicide glyphosate is a potent inhibitor of 5enolpyruvylshikimic acid-3-phosphate synthase. Biochem. Biophys. Res. Commun. 1980, 94 (4), 1207-1212.

(3) Heap, I. The International Survey of Herbicide Resistant Weeds. Online. Internet.

(4) Nandula, V. K. Glyphosate Resistance in Crops and Weeds. History, Development, and Management; Nandula, V. K., Ed.; John Wiley \& Sons, Inc. Hoboken, New Jersey, 2010.

(5) Livingston, M.; Fernandez-Cornejo, J.;Unger, J.; Osteen, C.; Schimmelpfennig, D.; Park, T.; Lambert, D. The economics of glyphosate resistance management in corn and soybean production. Economic Research Report No. (ERR-184), United States Department of Agriculture, 2015

(6) Yu, W. C.; Zhang, R.; Li, R. Z.; Guo, S. D. Isolation and characterization of glyphosateregulated genes in soybean seedlings. Plant Sci. 2007, 172 (3), 497-504.

(7) Zhu, J.; Patzoldt, W.; Shealy, R. Transcriptome response to glyphosate in sensitive and resistant soybean. J. Agric. Food Chem. 2008, 56 (15), 6355-6363.

(8) Ahsan, N.; Lee, D.-G.; Lee, K.-W.; Alam, I.; Lee, S.-H.; Bahk, J. D.; Lee, B.-H. Glyphosateinduced oxidative stress in rice leaves revealed by proteomic approach. Plant Physiol.

Biochem. 2008, 46 (12), 1062-1070.

(9) Trenkamp, S.; Eckes, P.; Busch, M.; Fernie, A. R. Temporally resolved GC-MS-based metabolic profiling of herbicide treated plants treated reveals that changes in polar primary metabolites alone can distinguish herbicides of differing mode of action. Metabolomics 2009, 5 (3), 277-291.

(10) Maroli, A. S.; Nandula, V. K.; Dayan, F. E.; Duke, S. O.; Gerard, P.; Tharayil, N. Metabolic profiling and enzyme analyses indicate a potential role of antioxidant systems in complementing glyphosate resistance in an Amaranthus palmeri biotype. J. Agric. Food Chem. 2015, 63 (41), 9199-9209.

(11) Lydon, J.; Duke, S. O. Glyphosate induction of elevated levels of hydroxybenzoic acids in higher-plants. J. Agric. Food Chem. 1988, 36 (4), 813-818.

(12) Becerril, J. M.; Duke, S. O.; Lydon, J. Glyphosate effects on shikimate pathway products in leaves and flowers of velvetleaf. Phytochemistry 1989, 28 (3), 695-699.

(13) De María, N.; Becerril, J. M.; García-Plazaola, J. I.; Hernández, A.; De Felipe, M. R.; Fernández-Pascual, M. New insights on glyphosate mode of action in nodular metabolism: Role of shikimate accumulation. J. Agric. Food Chem. 2006, 54 (7), 2621-2628.

(14) Orcaray, L.; Igal, M.; Marino, D.; Zabalza, A.; Royuela, M. The possible role of quinate in the mode of action of glyphosate and acetolactate synthase inhibitors. Pest Manag. Sci. 2010, 66 (3), 262-269.

(15) Zulet, A.; Gil-Monreal, M.; Villamor, J. G.; Zabalza, A.; van der Hoorn, R. A. L.; Royuela, 
M. Proteolytic pathways induced by herbicides that inhibit amino acid biosynthesis. PLoS One 2013, 8 (9), e73847.

(16) Zulet, A.; Gil-Monreal, M.; Zabalza, A.; van Dongen, J. T.; Royuela, M. Fermentation and alternative oxidase contribute to the action of amino acid biosynthesis-inhibiting herbicides. J. Plant Physiol. 2015, 175 (1), 102-112.

(17) Colombo, S. L.; Andreo, C. S.; Chollet, R. The interaction of shikimic acid and protein phosphorylation with PEP- carboxylase from the $\mathrm{C}_{4}$ dicot Amaranthus viridis.

Phytochemistry 2000, 48 (I), 55-59.

(18) Orcaray, L.; Zulet, A.; Zabalza, A.; Royuela, M. Impairment of carbon metabolism induced by the herbicide glyphosate. J. Plant Physiol. 2012, 169 (1), 27-33.

(19) Culpepper, A. S.; Grey, T.; Vencill, W. Glyphosate-resistant Palmer amaranth (Amaranthus palmeri) confirmed in Georgia. Weed Sci. 2006, 54 (4), 620-626.

(20) Gaines, T. A; Zhang, W.; Wang, D.; Bukun, B.; Chisholm, S. T.; Shaner, D. L.; Nissen, S. J.; Patzoldt, W. L.; Tranel, P. J.; Culpepper, A. S.; Grey T.L.; Webster, T.M.; Vencill, W.K.; Sammons, R.D.; Jiang, J.; Preston, C.; Leach, J.E.; Westra, P. Gene amplification confers glyphosate resistance in Amaranthus palmeri. Proc. Natl. Acad. Sci. U. S. A. 2010, 107 (3), 1029-1034.

(21) Sammons, R. D.; Gaines, T. A. Glyphosate resistance: State of knowledge. Pest Manag. Sci. 2014, 70 (9), 1367-1377.

(22) Lorentz, L.; Gaines, T. A; Nissen, S. J.; Westra, P.; Strek, H. J.; Dehne, H. W.; RuizSantaella, J. P.; Beffa, R. S. Characterization of glyphosate resistance in Amaranthus tuberculatus populations. J. Agric. Food Chem. 2014, 62 (32), 8134-8142.

(23) Chatham, L. A.; Wu, C.; Riggins, C. W.; Hager, A. G.; Young, B. G.; Gordon, K.; Tranel, P. $\mathrm{J}$. EPSPS Gene amplification is present in the majority of glyphosate-resistant illinois waterhemp (Amaranthus tuberculatus ) populations. Weed Technol. 2015, 29 (1), 48-55.

(24) Nandula, V. K.; Wright, A. A.; Bond, J. a.; Ray, J. D.; Eubank, T. W.; Molin, W. T. EPSPS amplification in glyphosate-resistant spiny amaranth (Amaranthus spinosus): A case of gene transfer via interspecific hybridization from glyphosate-resistant Palmer amaranth (Amaranthus palmeri). Pest Manag. Sci. 2014, 70 (12), 1902-1909.

(25) Wiersma, A. T.; Gaines, T. A.; Preston, C.; Hamilton, J. P.; Giacomini, D.; Robin Buell, C.; Leach, J. E.; Westra, P. Gene amplification of 5-enol-pyruvylshikimate-3-phosphate synthase in glyphosate-resistant Kochia scoparia. Planta 2014, 241 (2), 463-474.

(26) Salas, R. A.; Dayan, F. E.; Pan, Z.; Watson, S. B.; Dickson, J. W.; Scott, R. C.; Burgos, N. R. EPSPS gene amplification in glyphosate-resistant Italian ryegrass (Lolium perenne ssp. multiflorum) from Arkansas. Pest Manag. Sci. 2012, 68 (9), 1223-1230.

Salas, R. A; Scott, R. C.; Dayan, F. E.; Burgos, N. R. EPSPS gene amplification in glyphosate-resistant italian ryegrass ( Lolium perenne ssp. multiflorum ) populations from arkansas (United States). J. Agric. Food Chem. 2015, 63 (25), 5885-5893.

(28) Malone, J. M.; Morran, S.; Shirley, N.; Boutsalis, P.; Preston, C. EPSPS gene amplification in glyphosate-resistant Bromus diandrus. Pest Manag. Sci. 2015, Epub ahead of print, doi: 
10.1002/ps.4019.

(29) Chandi, A.; Milla-Lewis, S. R.; Giacomini, D.; Westra, P.; Preston, C.; Jordan, D. L.; York, A. C.; Burton, J. D.; Whitaker, J. R. Inheritance of evolved glyphosate resistance in a North Carolina Palmer amaranth (Amaranthus palmeri) Biotype. Int. J. Agron. 2012, 2012, 1-7.

(30) Labhilili, M.; Joudrier, P.; Gautier, M. F. Characterization of cDNAs encoding Triticum durum dehydrins and their expression patterns in cultivars that differ in drought tolerance. Plant Sci. 1995, 112 (2), 219-230.

(31) Hoagland, D. R.; Arnon, D. I. The water-culture method for growing plants without soil. Calif. Agric. Exp. Stn. Circ. 1950, 347 (347), 1-32.

(32) Koger, C. H.; Shaner, D. L.; Henry, W. B.; Nadler-Hassar, T.; Thomas, W. E.; Wilcut, J. W. Assessment of two nondestructive assays for detecting glyphosate resistance in horseweed (Conyza canadensis). Weed Sci. 2005, 53 (5), 559-566.

(33) Cromartie, T. H.; Polge, N. D. An improved assay for shikimic acid and its use as monitor for the activity of sulfosate. In Weed Science Society of America Proceedings; 2000; pp 4, 121.

(34) Seefeldt, S.S.; Jensen,J.E.; Fuerst, P.Log -logistic analysis of herbicide dose-response relationships. Weed Technol. 1995, 9 (2), 218-227.

(35) Hess, M.; Barralis, G.; Bleiholder, H. Use of the extended BBCH scale-general for the descriptions of the growth stages of mono- and dicotyledonous weed species. Weed Res. 1997, 37 (6), 433-441.

(36) Koger, C. H.; Shaner, D. L.; Krutz, L. J.; Walker, T. W.; Buehring, N.; Henry, W. B.; Thomas, W. E.; Wilcut, J. W. Rice (Oryza sativa) response to drift rates of glyphosate. Pest Manag. Sci. 2005, 61 (12), 1161-1167.

(37) Hoagland, R. E.; Jordan, R. H.; Teaster, N. D. Bioassay and characterization of several palmer amaranth (Amaranthus palmeri) biotypes with varying tolerances to glyphosate. Am. J. Plant Sci. 2013, 4 (05), 1029-1037.

(38) Zulet, A.; Zabalza, A.; Royuela, M. Phytotoxic and metabolic effects of exogenous quinate on Pisum sativum L. J. Plant Growth Regul. 2013, 37, 779-788.

(39) Zinellu, A.; Sotgia, S.; Posadino, A. M.; Pasciu, V.; Perino, M. G.; Tadolini, B.; Deiana, L.; Carru, C. Highly sensitive simultaneous detection of cultured cellular thiols by laser induced fluorescence-capillary electrophoresis. Electrophoresis 2005, 26 (6), 1063-1070.

(40) Zabalza, A.; Orcaray, L.; Gaston, S.; Royuela, M. Carbohydrate accumulation in leaves of plants treated with the herbicide chlorsulfuron or imazethapyr is due to a decrease in sink strength. J. Agric. Food Chem. 2004, 52 (25), 7601-7606.

(41) Gaston, S.; Zabalza, A.; González, E. M.; Arrese-Igor, C.; Aparicio-Tejo, P. M.; Royuela, M. Imazethapyr, an inhibitor of the branched-chain amino acid biosynthesis, induces aerobic fermentation in pea plants. Physiol. Plant. 2002, 114 (4), 524-532.

(42) Whitaker, J. R.; Burton, J. D.; York, A. C.; Jordan, D. L.; Chandi, A. Physiology of glyphosate-resistant and glyphosate-susceptible palmer amaranth (Amaranthus palmeri) 
biotypes collected from North Carolina. Int. J. Agron. 2013, 2013, 1-6.

(43) Culpepper, A S.; Whitaker, J. R.; MacRae, A. W.; York, A. C. Distribution of glyphosateresistant Palmer amaranth (Amaranthus palmeri) in Georgia and North Carolina during 2005 and 2006. J. Cotton Sci. 2008, 12 (3), 306-310.

(44) Mohseni-Moghadam, M.; Schroeder, J.; Ashigh, J. Mechanism of resistance and inheritance in glyphosate resistant Palmer amaranth ( Amaranthus palmeri) populations from New Mexico, USA. Weed Sci. 2013, 61 (4), 517-525.

(45) Ribeiro, D. N.; Pan, Z.; Duke, S. O.; Nandula, V. K.; Baldwin, B. S.; Shaw, D. R.; Dayan, F. E. Involvement of facultative apomixis in inheritance of EPSPS gene amplification in glyphosate-resistant Amaranthus palmeri. Planta 2014, 239 (1), 199-212.

(46) Gaines, T. A; Shaner, D. L.; Ward, S. M.; Leach, J. E.; Preston, C.; Westra, P. Mechanism of resistance of evolved glyphosate-resistant Palmer amaranth (Amaranthus palmeri). J. Agric. Food Chem. 2011, 59 (11), 5886-5889.

Vila-Aiub, M. M.; Goh, S. S.; Gaines, T. A; Han, H.; Busi, R.; Yu, Q.; Powles, S. B. No fitness cost of glyphosate resistance endowed by massive EPSPS gene amplification in Amaranthus palmeri. Planta 2014, 239 (4), 793-801.

(48) Teaster, N. D.; Hoagland, R. E. Characterization of glyphosate resistance in cloned Amaranthus palmeri plants. Weed Biol. Manag. 2014, 14 (1), 1-10.

(49) Alarcón-Reverte, R.; García, A.; Watson, S. B.; Abdallah, I.; Sabaté, S.; Hernández, M. J.; Dayan, F. E.; Fischer, A. Concerted action of target-site mutations and high EPSPS activity in glyphosate-resistant junglerice (Echinochloa colona) from California. Pest Manag. Sci. 2015, 71 (530), 996-1007.

(50) Baerson, S. R.; Rodriguez, D. J.; Tran, M.; Feng, Y.; Biest, N. a; Dill, G. M. Glyphosateresistant goosegrass. Identification of a mutation in the target enzyme 5enolpyruvylshikimate-3-phosphate synthase. Plant Physiol. 2002, 129 (3), 1265-1275.

(51) Baerson, S. R.; Rodriguez, D. J.; Biest, N. a.; Tran, M.; You, J.; Kreuger, R. W.; Dill, G. M.; Pratley, J. E.; Gruys, K. J. Investigating the mechanism of glyphosate resistance in rigid ryegrass (Lolium ridigum). Weed Sci. 2002, 50 (6), 721-730.

(52) Garg, B.; Vaid, N.; Tuteja, N. In-silico analysis and expression profiling implicate diverse role of EPSPS family genes in regulating developmental and metabolic processes. BMC Res. Notes 2014, 7 (1), 58.

(53) Maeda, H.; Dudareva, N. The shikimate pathway and aromatic amino acid biosynthesis in plants. Annu. Rev. Plant Biol. 2012, 63 (1), 73-105.

(54) Tohge, T.; Watanabe, M.; Hoefgen, R.; Fernie, A. R. Shikimate and phenylalanine biosynthesis in the green lineage. Front. Plant Sci. 2013, 4, Article 62.

(55) Tzin, V.; Galili, G. New Insights into the shikimate and aromatic amino acids biosynthesis pathways in plants. Mol. Plant 2010, 3 (6), 956-972.

(56) Takatsuji, H.; Mori, M.; Benfey, P. N.; Ren, L.; Chua, N. Characterization of a zinc finger DNA-binding protein expressed specifically in Petunia petals and seedlings. EMBO J. 1988, 
$1(1), 241-249$.

(57) Galili, G.; Hofgen, R. Metabolic engineering of amino acids and storage proteins in plants. Metab. Eng. 2002, 4 (1), 3-11.

(58) Liu, Y.; Zhang, Y.; Liu, Y.; Lu, W.; Wang, G. Metabolic effects of glyphosate on transgenic maize expressing a G2-EPSPS gene from Pseudomonas fluorescens. J. Plant Biochem.

Biotec. 2015, 24 (2), 233-241.

(59) Vivancos, P. D.; Driscoll, S. P.; Bulman, C. A.; Ying, L.; Emami, K.; Treumann, A.; Mauve, C.; Noctor, G.; Foyer, C. H. Perturbations of amino acid metabolism associated with glyphosate-dependent inhibition of shikimic acid metabolism affect cellular redox homeostasis and alter the abundance of proteins involved in photosynthesis and photorespiration. Plant Physiol. 2011, 157 (1), 256-268.

(60) Moldes, C. A.; Medici, L. O.; Abrahao, O. S.; Tsai, S. M.; Azevedo, R. A. Biochemical responses of glyphosate resistant and susceptible soybean plants exposed to glyphosate. Acta Physiol. Plant. 2008, 30 (4), 469-479.

(61) Petersen, I. L.; Hansen, H. C. B.; Ravn, H. W.; Sørensen, J. C.; Sørensen, H. Metabolic effects in rapeseed (Brassica napus L.) seedlings after root exposure to glyphosate. Pestic. Biochem. Physiol. 2007, 89 (3), 220-229.

(62) Tzin, V.; Malitsky, S.; Zvi, M. M. Ben; Bedair, M.; Sumner, L.; Aharoni, A.; Galili, G. Expression of a bacterial feedback-insensitive 3-deoxy-d-arabino-heptulosonate 7-phosphate synthase of the shikimate pathway in Arabidopsis elucidates potential metabolic bottlenecks between primary and secondary metabolism. New Phytol. 2012, 194 (2), 430-439.

(63) Armendáriz, O.; Miriam, G.-M.; Zulet, A.; Zabalza, A.; Royuela, M. Both foliar and residual applications of herbicides that inhibit amino acid biosynthesis induce alternative respiration and aerobic fermentation in pea roots. Plant Biol. 2015, E-pub ahead of print. doi:100.1111/plb.12412.

(64) Shaner, D. L.; Beckie, H. J. The future for weed control and technology. Pest Manag. Sci. 2014, 70 (9), 1329-1339. 


\section{FIGURE CAPTIONS}

\section{$530 \quad$ Figure 1.}

531 A. Dose-response of the shoot dry weight accumulation in glyphosate-susceptible (NC-S) and -

532 resistant (NC-R) Amaranthus palmeri plants over the 5 days following glyphosate application,

533 as a percentage of the untreated plants. Log-logistic dose-response curves.

534 B. Shikimate content in the leaves of glyphosate-susceptible (NC-S) and -resistant (NC-R)

535 Amaranthus palmeri plants 5 days after spraying with glyphosate. Means $\pm \mathrm{SE}(\mathrm{n}=4-7)$.

536 Figure 2. Effect of glyphosate concentration on shikimate levels in excised leaf discs from

537 glyphosate-susceptible ((NC-S) and -resistant (NC-R) Amaranthus palmeri biotypes. Means \pm

538 SE $(n=16)$.

$539 \quad$ Figure 3.

540 A: Amaranthus palmeri genomic copy number of 5-enolpyruvylshikimate-3-phosphate synthase

541 (EPSPS) relative to acetolactate synthase (ALS) in glyphosate-susceptible (NC-S) and -resistant

542 (NC-R) biotypes. Mean $\pm \mathrm{SE}(\mathrm{n}=9)$.

543 B: EPSPS protein levels in the leaves of glyphosate-susceptible (NC-S) and -resistant (NC-R)

544 Amaranthus palmeri populations untreated (0) or treated with 0.84 or $2.52 \mathrm{~kg} \mathrm{ha}^{-1}$ glyphosate, 3

545 days after application. Top: A representative sample blot is shown, and $\mu \mathrm{g}$ protein loaded/well

546 is indicated. Bottom: Normalized EPSPS quantity. Mean $\pm \operatorname{SE}(n=3)$.

547 C: Effect of glyphosate on EPSPS activity in leaves of glyphosate-susceptible (NC-S) and -

548 resistant (NC-R) Amaranthus palmeri populations (3 days after application). Means $\pm \mathrm{SE}(\mathrm{n}=4)$.

\section{$549 \quad$ Figure 4.}

550 Total amino acid content in leaves (A) and roots (C) of untreated plants of glyphosate-

551 susceptible (NC-S) and -resistant (NC-R) Amaranthus palmeri populations. The effect of

552 glyphosate on the total amino acid content in leaves (B) and roots (D) 3 days after treatment.

553 Means \pm SE ( $n=6-9)$. The symbol * indicates significant differences between control plants

554 (without herbicide) of each population. Different capital letters in the NC-R population and

555 different lowercase letters in the NC-S population indicate significant differences between

556 treatments ( $\mathrm{p}$ value $\leq 0.05$ ).

\section{Figure 5}

558 Aromatic amino acid (Phe, Tyr and Trp) content in leaves (A) and roots (C) of untreated plants

559 of glyphosate-susceptible (NC-S) and -resistant (NC-R) Amaranthus palmeri populations. 
560 Effect of glyphosate on aromatic amino acid (Phe, Tyr, Trp) content with respect to the total

561 free amino acids (percent of the total free amino acids) in leaves (B) and roots (D) 3 days after

562 treatment. Means $\pm \mathrm{SE}(\mathrm{n}=6-9)$. Different capital letters for the NC-R population and different

563 lowercase letters for the NC-S population indicate significant differences between treatments ( $p$

564 value $\leq 0.05$ ). The letters embedded in the columns indicate differences for each individual

565 amino acid, and letters above the columns indicate differences between the sums of aromatic

566 amino acids.

567 Figure 6. Effect of glyphosate on total soluble sugar (fructose, glucose and sucrose) and starch

568 contents in leaves and roots of glyphosate-susceptible (NC-S) and -resistant (NC-R)

569 Amaranthus palmeri populations (3 days after application). Means $\pm \mathrm{SE}(\mathrm{n}=6-9)$. The symbol *

570 indicates significant differences between control plants (without herbicide) of each population.

571 Different capital letters for the NC-R population and different lowercase letters for the NC-S

572 population indicate significant differences between treatments ( $p$ value $\leq 0.05$ ).

573 Figure 7. Effect of glyphosate on pyruvate decarboxylase and alcohol dehydrogenase enzymatic

574 activities in roots of glyphosate-susceptible (NC-S) and -resistant (NC-R) Amaranthus palmeri

575 populations (3 days after application). Means $\pm \mathrm{SE}(\mathrm{n}=6-9)$. The symbol * highlights significant

576 differences between control plants (without herbicide) of each population. Different capital

577 letters for the NC-R population and different lowercase letters for the NC-S population indicate

578 significant differences between treatments ( $\mathrm{p}$ value $\leq 0.05$ ).

579 Supplementary Information Figure 1. Effect of glyphosate on free amino acid content in

580 leaves of glyphosate-resistant (NC-R) and -susceptible (NC-S) Amaranthus palmeri populations

581 ( 3 days after application). When not indicated $\mathrm{Y}$-axis units are $\mu \mathrm{mol} \mathrm{g} \mathrm{g}^{-1}$ fresh weight. Means \pm

582 SE (n=6-9). The symbol * highlights significant differences between control plants (without

583 herbicide) of each population. Different capital letters for the NC-R population and different

584 lowercase letters for the NC-S population indicate significant differences between treatments ( $p$ 585 value $\leq 0.05$ ).

586

587 Supplementary Information Figure 2. Effect of glyphosate on free amino acid content in

588 roots of glyphosate-resistant (NC-R) and -susceptible (NC-S) Amaranthus palmeri populations

589 (3 days after application). When not indicate $\mathrm{Y}$-axis units are $\mu \mathrm{mol} \mathrm{g}{ }^{-1}$ fresh weight. Means $\underline{ \pm}$

590 SE (n=6-9). The symbol * highlights significant differences between control plants (without

591 herbicide) of each population. Different capital letters for the NC-R population and different

592 lowercase letters for the NC-S population indicate significant differences between treatments ( $p$

593 value $\leq 0.05)$. 


\section{TABLE OF CONTENTS}

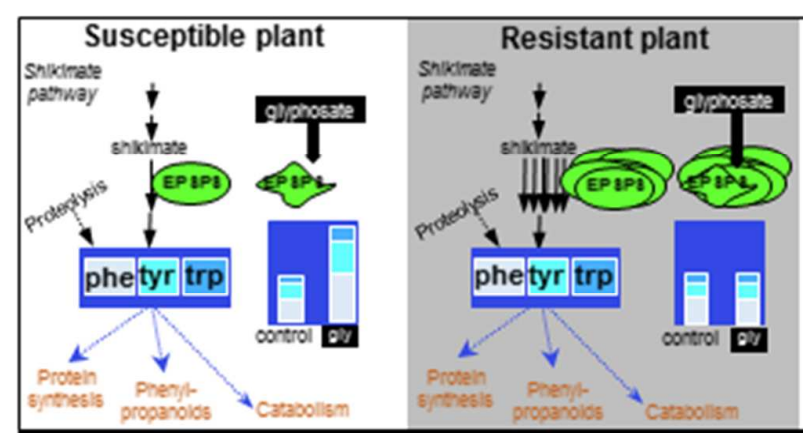




\section{Susceptible plant}

Resistant plant shRabmouBrab fos\&griculturalsandeFood Chemistry

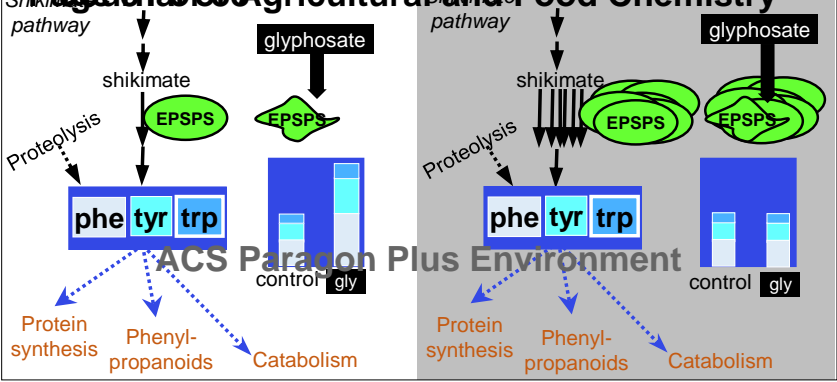



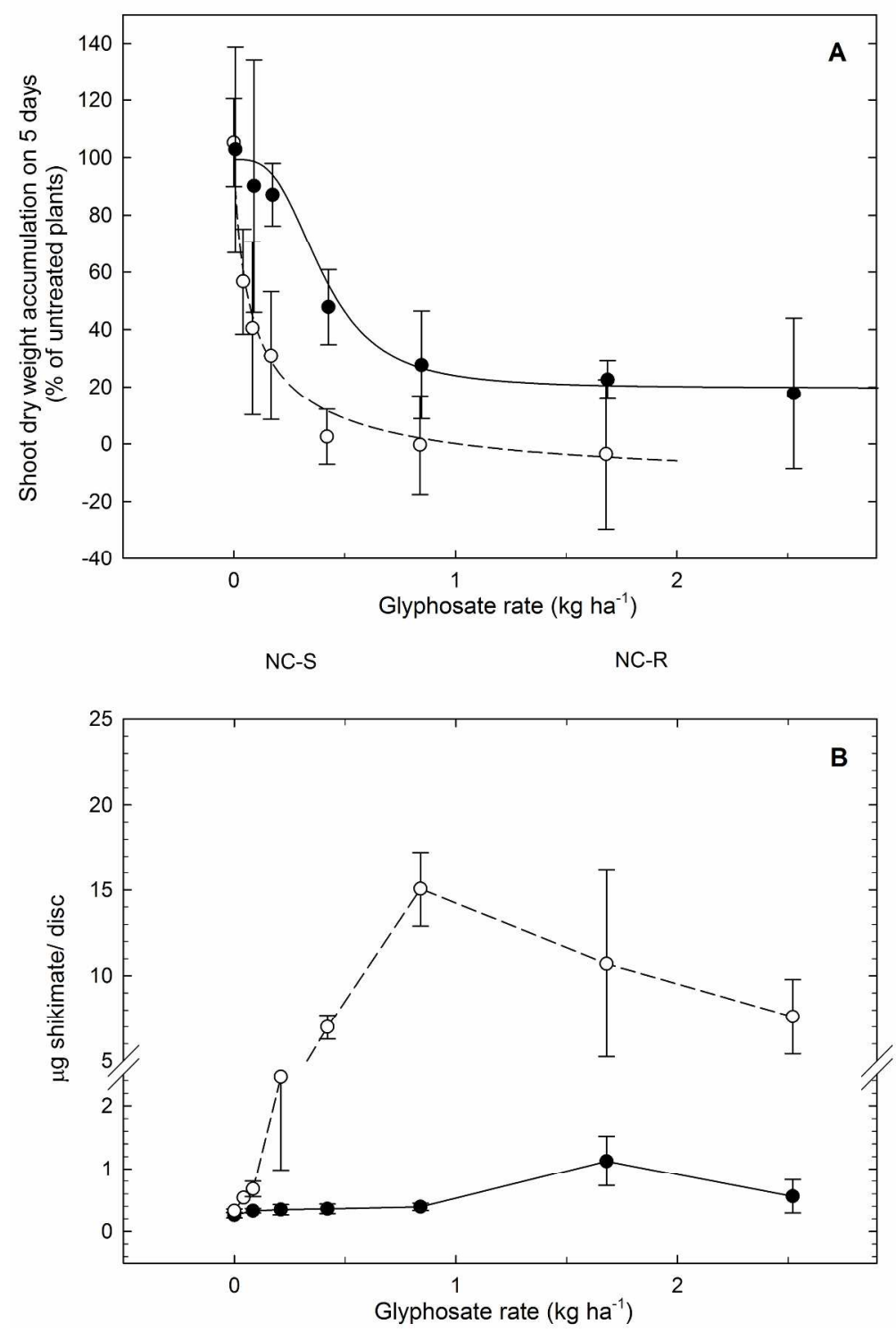

Figure 1.

A. Dose-response of the shoot dry weight accumulation in glyphosate-susceptible (NC-S) and -resistant (NC-R) Amaranthus palmeri plants over the 5 days following glyphosate application, as a percentage of the untreated plants. Log-logistic dose-response curves.

B. Shikimate content in the leaves of glyphosate-susceptible (NC-S) and -resistant (NC-R) Amaranthus palmeri plants 5 days after spraying with glyphosate. Means $\pm \operatorname{SE}(n=4-7)$.

$230 \times 354 \mathrm{~mm}(300 \times 300 \mathrm{DPI})$ 


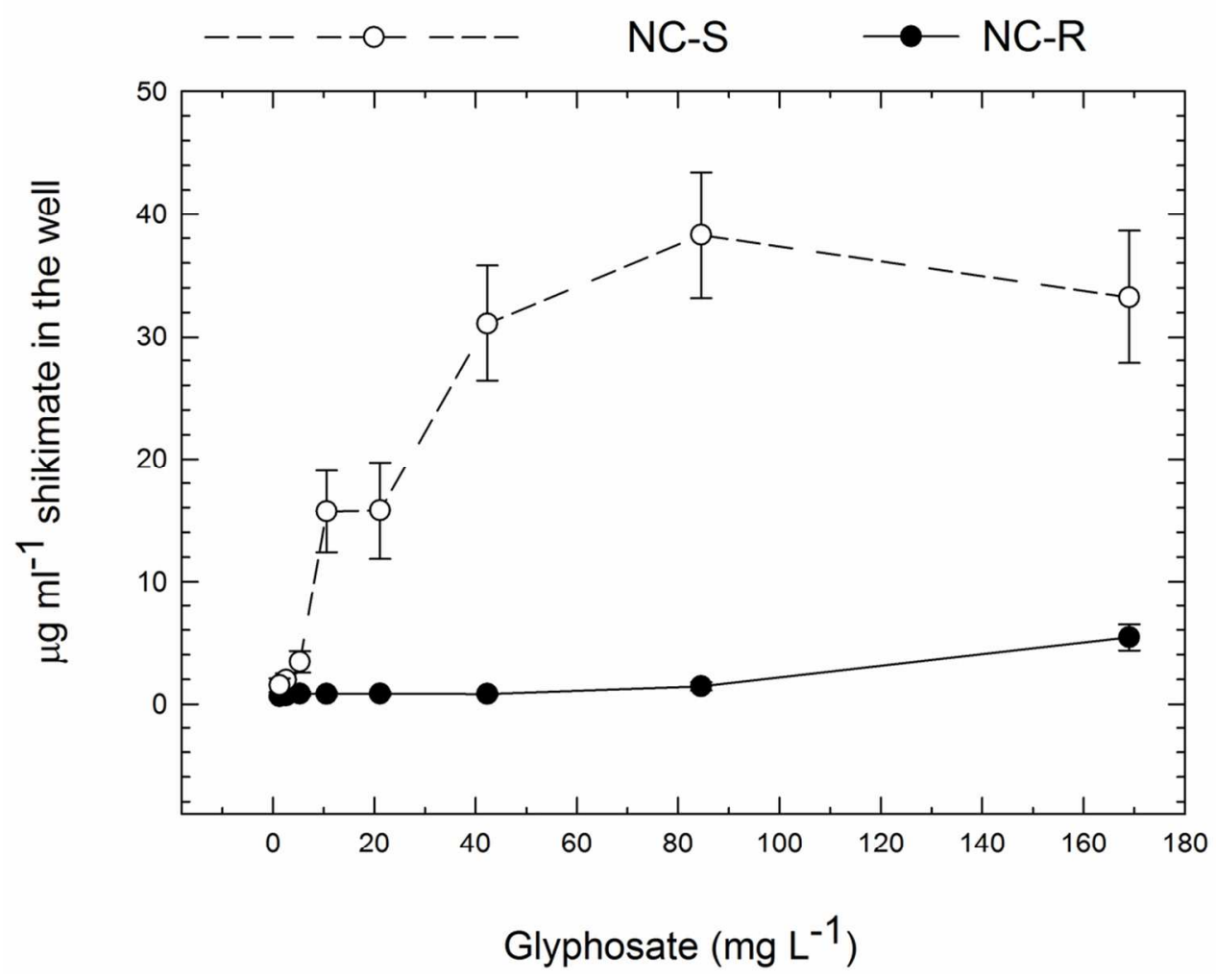

Figure 2. Effect of glyphosate concentration on shikimate levels in excised leaf discs from glyphosatesusceptible ((NC-S) and -resistant (NC-R) Amaranthus palmeri biotypes. Means \pm SE $(n=16)$. $101 \times 82 \mathrm{~mm}(300 \times 300 \mathrm{DPI})$ 

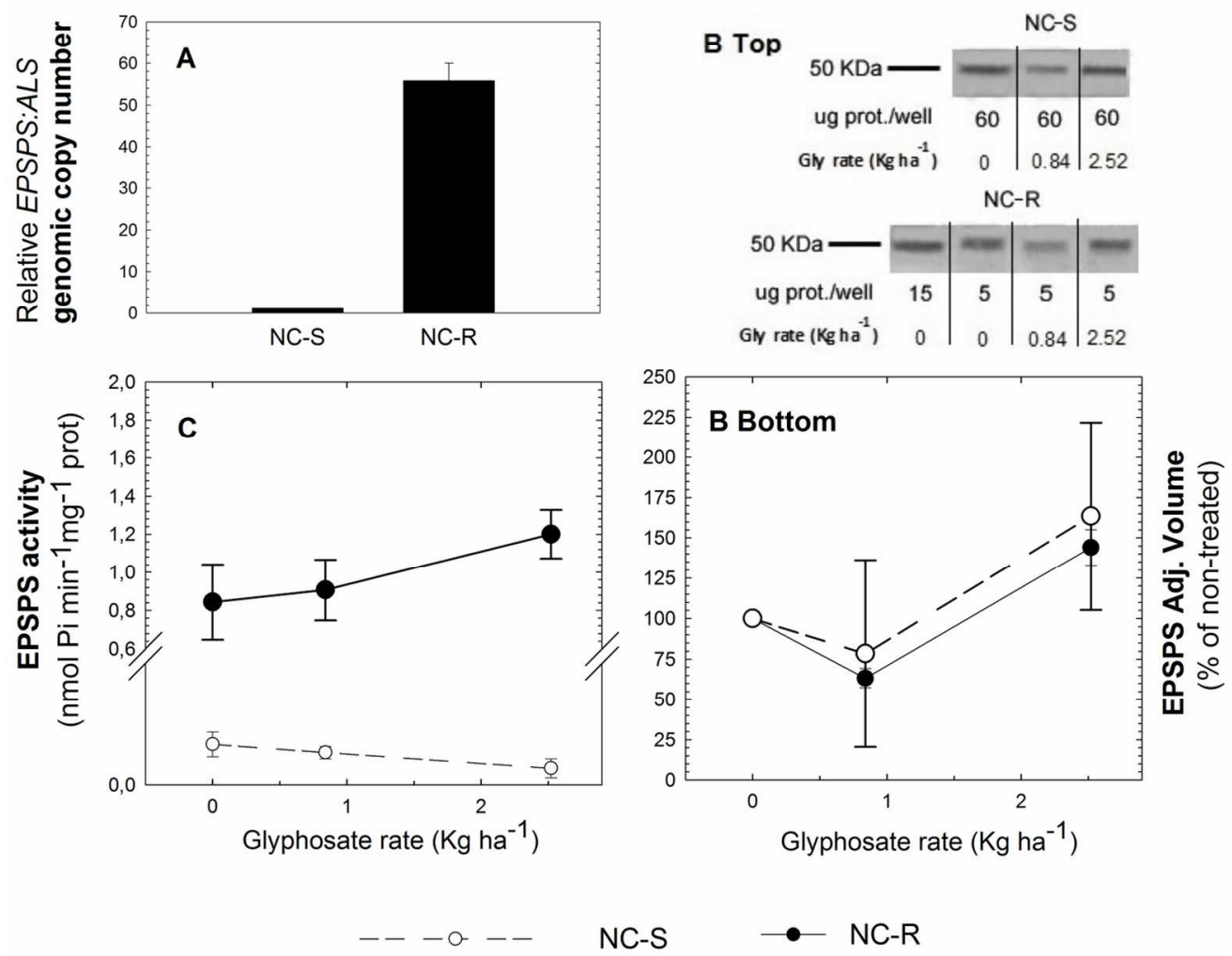

Figure 3.

A: Amaranthus palmeri genomic copy number of 5-enolpyruvylshikimate-3-phosphate synthase (EPSPS) relative to acetolactate synthase (ALS) in glyphosate-susceptible (NC-S) and -resistant (NC-R) biotypes. Mean \pm SE $(n=9)$.

B: EPSPS protein levels in the leaves of glyphosate-susceptible (NC-S) and -resistant (NC-R) Amaranthus palmeri populations untreated (0) or treated with 0.84 or $2.52 \mathrm{~kg}$ ha-1 glyphosate, 3 days after application. Top: A representative sample blot is shown, and $\mu \mathrm{g}$ protein loaded/well is indicated. Bottom: Normalized EPSPS quantity. Mean \pm SE $(n=3)$.

C: Effect of glyphosate on EPSPS activity in leaves of glyphosate-susceptible (NC-S) and -resistant (NC-R) Amaranthus palmeri populations ( 3 days after application). Means $\pm \operatorname{SE}(n=4)$.

$128 \times 110 \mathrm{~mm}(300 \times 300 \mathrm{DPI})$ 

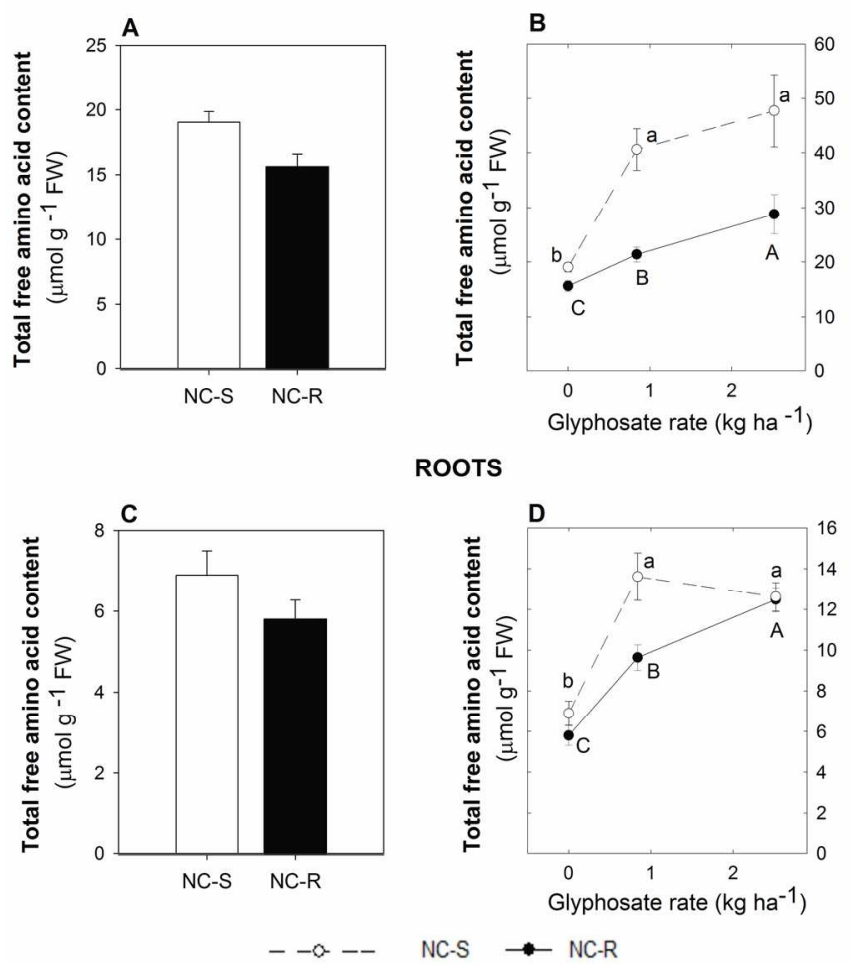

ROOTS

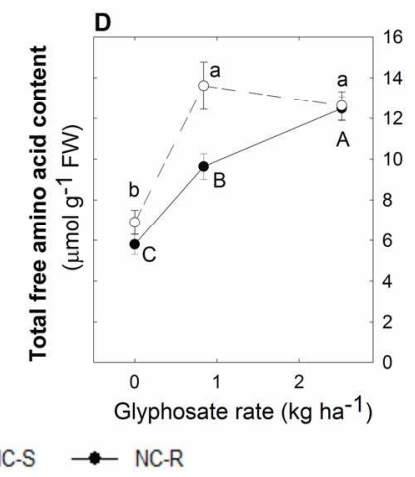

Figure 4.

Total amino acid content in leaves (A) and roots (C) of untreated plants of glyphosate- susceptible (NC-S) and -resistant (NC-R) Amaranthus palmeri populations. The effect of glyphosate on the total amino acid content in leaves (B) and roots (D) 3 days after treatment. Means \pm SE $(n=6-9)$. The symbol * indicates significant differences between control plants (without herbicide) of each population. Different capital letters in the NC-R population and different lowercase letters in the NC-S population indicate significant differences between treatments ( $p$ value<0.05).

$170 \times 130 \mathrm{~mm}(300 \times 300 \mathrm{DPI})$ 


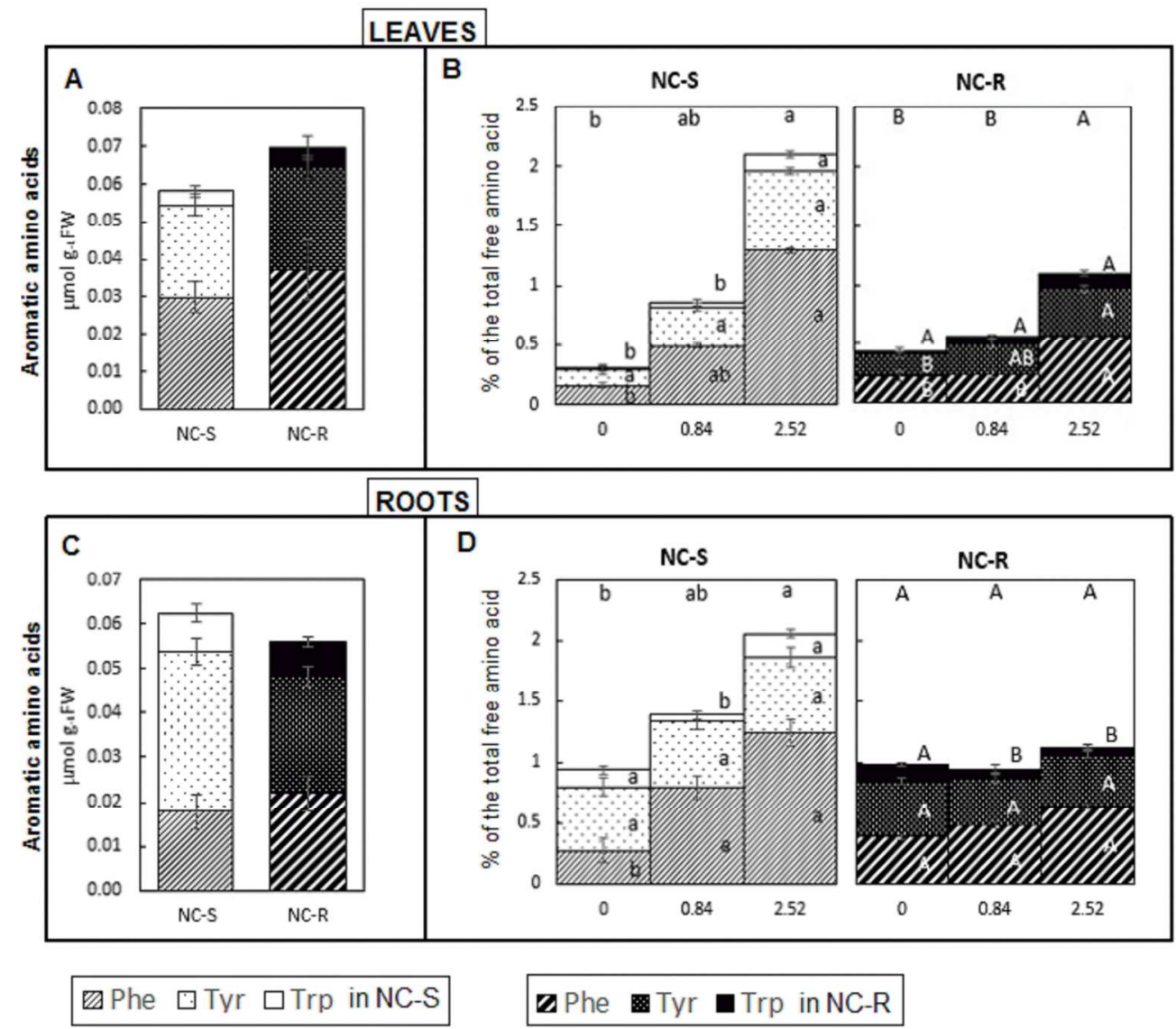

Figure 5

Aromatic amino acid (Phe, Tyr and Trp) content in leaves (A) and roots (C) of untreated plants of glyphosate-susceptible (NC-S) and -resistant (NC-R) Amaranthus palmeri populations. Effect of glyphosate on aromatic amino acid (Phe, Tyr, Trp) content with respect to the total free amino acids (percent of the total free amino acids) in leaves (B) and roots (D) 3 days after treatment. Means \pm SE $(n=6-9)$. Different capital letters for the NC-R population and different lowercase letters for the NC-S population indicate significant differences between treatments ( $p$ value $<0.05$ ). The letters embedded in the columns indicate differences for each individual amino acid, and letters above the columns indicate differences between the sums of aromatic amino acids. 


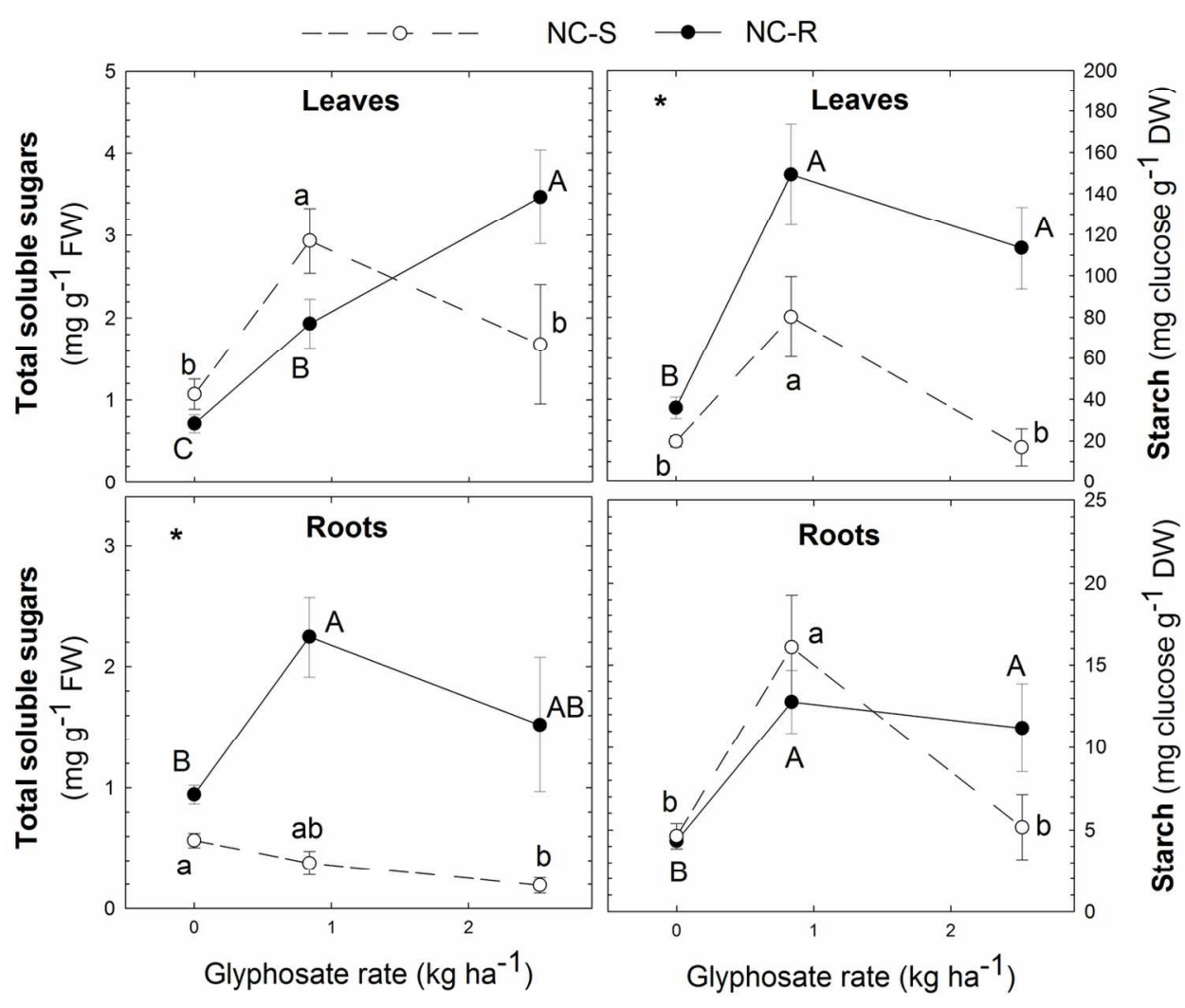

Figure 6. Effect of glyphosate on total soluble sugar (fructose, glucose and sucrose) and starch contents in leaves and roots of glyphosate-susceptible (NC-S) and -resistant (NC-R) Amaranthus palmeri populations (3 days after application). Means \pm SE $(n=6-9)$. The symbol $*$ indicates significant differences between control plants (without herbicide) of each population. Different capital letters for the NC-R population and different lowercase letters for the NC-S population indicate significant differences between treatments ( $p$ value $<0.05)$.

$125 \times 105 \mathrm{~mm}(300 \times 300 \mathrm{DPI})$ 


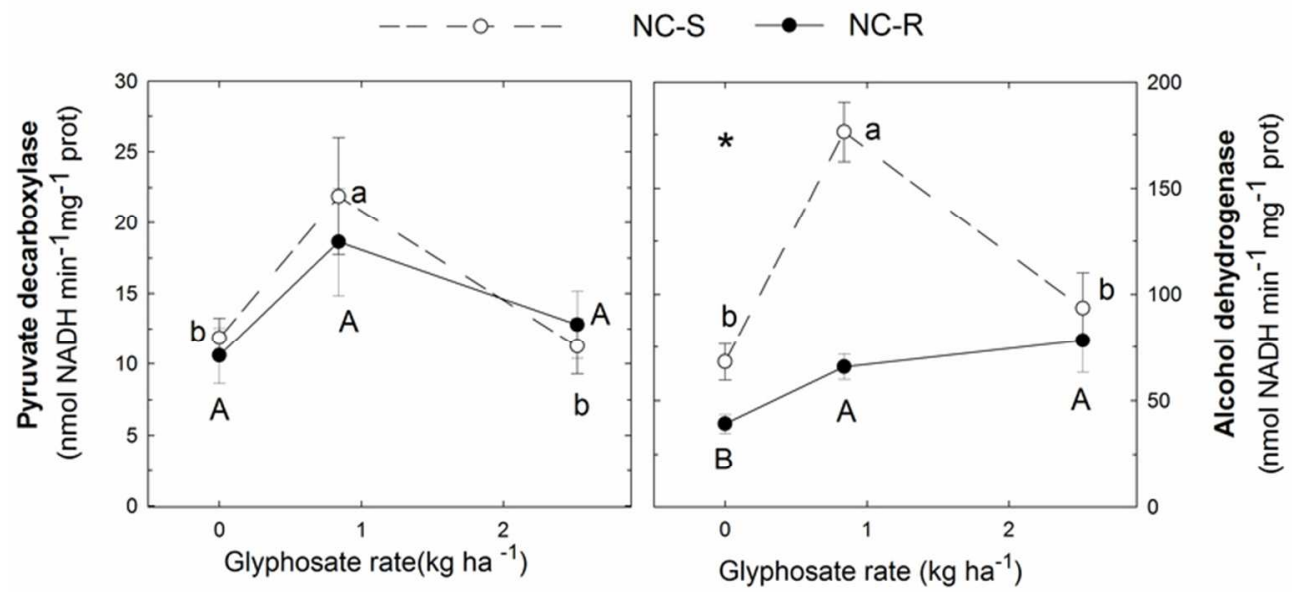

Figure 7. Effect of glyphosate on pyruvate decarboxylase and alcohol dehydrogenase enzymatic activities in roots of glyphosate-susceptible (NC-S) and -resistant (NC-R) Amaranthus palmeri populations (3 days after application). Means \pm SE $(n=6-9)$. The symbol $*$ highlights significant differences between control plants

(without herbicide) of each population. Different capital letters for the NC-R population and different lowercase letters for the NC-S population indicate significant differences between treatments ( $p$ value $<0.05)$.

$72 \times 34 \mathrm{~mm}(300 \times 300$ DPI $)$ 